\title{
VALERIA A PENA DECOLONIZAR AS TERMINOLOGIAS DA MBIRA?
}

\author{
Micas Orlando Silambo ${ }^{1}$
}

RESUMO: A nomenclatura dos instrumentos musicais tradicionais africanos na contemporaneidade contempla uma diversidade de questões que remetem-nos a uma reflexão. Entre as importantes discussões que permeiam a atribuição das terminologias a esses instrumentos musicais, o contexto da sua produção (sujeitos, situações, espaços, épocas, sons, experiências, narrativas e memórias) tem ocupado lugar de destaque. Este artigo reflete sobre aspectos que têm sido considerados na atribuição da nomenclatura da Mbira (instrumento musical tradicional africano), apontando perspectivas que podem fundamentar a redefinição das terminologias pela sua implicação na construção contemplativa da humanidade. $O$ trabalho tem como base pesquisa bibliográfica, observação participante, entrevista semiestruturada e experiências do autor como estudioso e executante da Mbira. A partir das discussões realizadas, o texto aponta aspectos importantes que fundamentam a valorização do meio da sua produção na atribuição das terminologias dos instrumentos africanos, proporcionando um ajuste dos produtos ideológicos do pensamento mundial sobre o "outro".

Palavras-chave: Mbira. Terminologia. Colonialidade. Decolonialidade.

\section{APRESENTAÇÃO E BASES FUNDAMENTAIS}

Este artigo é um recorte de uma pesquisa desenvolvida durante o Curso de Graduação que foi se intensificando com o meu envolvimento musical com a Mbira fora e dentro da academia através de questionamentos que foram-se operando, também, durante o curso de Pós-graduação "mestrado", bem como as literaturas que têm sustentado o doutorado. Assim, o trabalho tem como base uma pesquisa bibliográfica, articulada com uma observação participativa, entrevista semiestruturada e minhas experiências no campo de pesquisa.

O texto propõe uma reflexão sobre as terminologias da Mbira (figura 1), um dos idiofones $^{2}$ dedilhado de altura definida com afinação fixa típico na região abaixo da bacia do vale do Rio Zambeze, uma região que compreende a maior parte da Rodésia do sul (Zimbabwe), sul e centro de Moçambique, sul e leste da Zâmbia, sul do Malawi e norte de Transvaal na África do Sul (TRACEY, 1972, p. 85). Trata-se de um instrumento constituído por lamelas (palhetas ou teclas) metálicas ou vegetais executadas pelo polegar direito $(\mathrm{Pd})$, polegar esquerdo $(\mathrm{Pe})$ e indicador direito (Id), conforme a figura 1, podendo por vezes usar-se o indicador esquerdo (Ie).

1 Instituição: Universidade Federal da Paraíba, Orcid: https://orcid.org/0000-0002-4682-043X, E-mail: yanikmicas@gmail.com 2 Denominam-se idiofones aqueles instrumentos cujo material soa por si: são os sinos, os chocalhos, os gongos, os paus-de chuva, as marimbas. etc. (HORNBOSTEL; SACHS, 1961). 


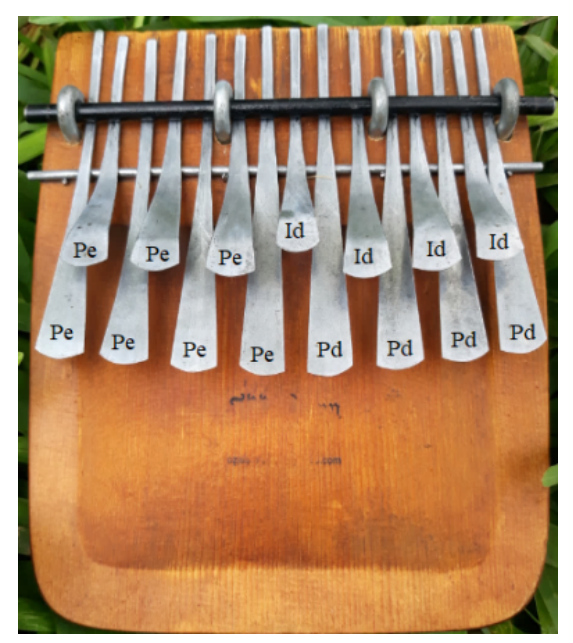

Figura 1 - Mbira (MACOO³, Janeiro, 2019).

No tocante a sua distribuição geográfica destaca-se que os diversos formatos deste instrumento podem ser encontrados na África do Sul, norte da Etiópia e Níger, oeste de Gâmbia, sudeste de Uganda, Congo, Zimbabwe, Angola, Moçambique, Tanzânia, Zâmbia, Malawi. Contudo, as áreas de maior concentração incluem Congo (ex-Zaire), Zimbabwe, centro e sul de Moçambique, sul e leste da Zâmbia, norte de Transvaal na África do Sul e uma parte de Angola (BLACKING, 1961; BERLINER, 1978; JONES, 1950; KAUFFMAN, 1970; TRACEY, 1972, 1974, 1989; DUARTE, 1980; DIAS, 1986, GUMBORESHUMBA, 2009; KUBIK, 2002; SILAMBO, 2012).

Os etnomusicólogos usam o termo lamelofone para classificar, genericamente, este instrumento uma vez que é um termo neutro da família dos instrumentos nas línguas europeias e evita confusões semânticas (KUBIK, 2002, p. 6). Este termo foi uma tentativa que os etnomusicólogos encontraram para a substituição dos termos "piano de polegar", "piano de mão" e "piano de dedo", tópico que detalharei no próximo item. Aqui, importa referir que o lamelofone é definido como um termo que denota uma grande família de instrumentos musicais difundidos na África Subsaariana cujo som é produzido dentro ou fora de um ressoador (caixa, cabaça, lata) pela vibração de lamelas finas ou linguetas de metal, madeira ou outro material dedilhado pelos polegares ou indicadores (NKETIA, 1979, p. 77; KAUFFMAN, 1980, p. 497; GUMBORESHUMBA, 2009, p. 17). Compreende-se que os instrumentos musicais tradicionais africanos têm sido um assunto de grande interesse para os etnomusicólogos, mas é preciso questionar o por quê da aplicação de termos neutros das línguas europeias. Será que estes instrumentos não têm nomes? Será que eles não estão vinculados a alguma tradição?

Este texto, responde, em primeiro lugar, à necessidade de rever e demonstrar o vínculo das terminologias da Mbira com os sujeitos, práticas, situações, espaços e épocas, aproveitando as pequeníssimas rachas ${ }^{4}$ que o século XXI tem proporcionado para o ajuste dos produtos ideológicos do pensamento mundial sobre as nossas circunstâncias "outro". Reflitamos um pouco sobre esta frase que a componho em suspense: A viola e o violino são instrumentos quase similares em sua estrutura e técnica de execução, mas um é viola e outro é violino.

3 Ozias Macoo é um fabricante dos instrumentos musicais tradicionais e convencionais com maior incidência para a Mbira. 4 A palavra racha é usada neste artigo com dois sentidos: primeiro, refere-se às aberturas que têm sido dadas para abordar sobre culturas locais e tradicionais; segundo, como uma forma de deixar claro que os estudos culturais nunca são completos, apresentando lacunas que configura futuros estudos. 
Trata-se de um texto que devia ter sido escrito em uma das mais de 2000 línguas ou 8000 "dialetos" de origem bantu (Swahili, Shona, Nyanja (XiChewa), Makhuwa, XiTsonga, Ndau, Yoruba, Umbundu, Zulu, Oshiwambo, etc.) existente na África, os quais têm sido amplamente usados pelos fazedores da Música de Mbira, porém estes idiomas (classes, grupos, ramificações) não são abertamente aceites pela hegemonia global que comanda a guerrilha das publicações académicas e científicas em quase todo mundo.

Lendo Walter (2009) e outros entendo que o conhecimento científico é encarado e valorizado como tal se transmitido através de certas línguas de origem europeia (Inglês, Francês, Alemão, Português e Espanhol). "Não pretendo iniciar uma guerra territorial com essa última observação, apenas para sublinhar a pertinência das línguas africanas para a compreensão da Música Africana. Infelizmente, a importância da linguagem para o estudo da música ainda não foi completamente aceita (AGAWU, 2001, p. 10) .

Assim, embora reconheço que as línguas hegemônicas carregam uma bagagem insuficiente para a compreensão da Música Africana, apropriei-me silenciosamente do português para favorecer esse espaço de poder expressivo da cultura e ciência dos Vachayi ou Vatovi va Timbira (executantes de Mbiras) como forma de demonstrar que "O conhecimento das línguas subalternas (minorizadas, diriam os sociolinguistas) é algo que pode ser estudado, mas não é um conhecimento válido a ser incorporado como um conhecimento paradigmático de pensar e viver" (GARCÉS, 2007, p. 226)7. Mas o que realmente desperta a minha atenção é a importância relativa de poder dar pensamentos, ainda que brutos ou sutis, sobre um tipo de força que a língua materna permite contra o fato de poder participar de movimentos de pensamento para os quais apenas "estrangeiros" ou, em alguns casos, idiomas "literários" podem dar acesso (GEERTZ, 1973, p. 241).

Em todo caso deixo um grito ambicioso e firme por um espaço crescente sobre as práticas musicais tradicionais verdadeiras com expectativa de que este texto, em segundo lugar, transforme sucessivamente aqueles que lutaram e continuam lutando pelo silenciamento das vozes ancestrais por golpe, batota, afogamento, opressão, asfixia, estrangulamento, encobrimento, ocultismo, enfim uma lista de epistemicídios "culturais"que vêm sendo cometidos para invisibilizar a ancestralidade da cultura musical Africana. Pesquisadores como Santos e Menezes (2010) frisam que os epistemicídios são assassinatos simbólicos que, promovidos pela imposição de uma cultura à outra, naturalizam a morte de formas de pensar, de maneiras de ser, de perspectivas de viver, subalternizando ou matando tudo o que é diferente da tendência dominante.

O repúdio contra os epistemicídios atuais implica para nós "os outros", pelo menos, uma aceitação de propostas interculturais que caminham por um diálogo compartilhado de tradições na construção humana do saber ser e estar diante do diferente. Essa é a superação que pode operar na luta pelo equilíbrio da lógica binária que estrutura a dinâmica social dos

5 I do not mean to start a territorial war with that last remark, only to underline the pertinence of African languages for the understanding of African music. Unfortunately, the importance of language for music study has still not been completely accepted (AGAWU, 2001, p. 10).

6 A expressão Vachayi va Timbira (singular Muchayi wa Mbira) é encontrada em duas variantes da língua xiTsonga, o xiRhonga e xiChangana, faladas na região Sul de Moçambique.

$7 \mathrm{El}$ conocimiento de las lenguas subalternas (minorizadas, dirían los sociolingüistas) es algo que se puede estudiar, pero no es un conocimiento válido para incorporar como conocimiento paradigmático del pensar y del vivir (GARCÉS, 2007, p. 226). 
laços da nossa sujeição como povos que procuram uma consciência libertadora das distinções modernas: autonomia-dependência, avançado-atrasado, humanas-exatas, local-global, periferia-central, universidade-sociedade, mestre-professor, alfabeto-analfabeto, entre outras.

A minha pretensão, portanto, é olhar para a cultura Africana num espaço da Música de Mbira e trazer discussões que possam sustentar ou não a necessidade de decolonizar ${ }^{8}$ as terminologias da Mbira. A genealogia de um pensamento decolonial articula culturas espalhadas pelo planeta e oferece outras modalidades sociais e subjetivas de caráter pluriversal e não simplesmente universal. Assim, cada nó da rede dessa genealogia é um ponto de decolagem e abertura que reintroduz linguagens, memórias, organizações sociais, subjetividades e misérias dos legados imperiais (MIGNOLO, 2007, p. 44). Para, de fato, sugerir mudanças nas terminologias da Mbira, precisamos não apenas admitir a sua importância, mas também sermos capazes de ouvir, assumir e adotar procedimentos decoloniais africanos que são produzidos em contextos de re-existência "como práticas insurgentes que fraturam a modernidade/colonialidade e tornam possível outras maneiras de ser, estar, pensar, saber, sentir, existir e viver-com" (WALSH, 2013, p. 19).

Assim, inicialmente apresento e discuto as terminologias da Mbira como foram sempre passadas pela colonialidade que se constituiu como a hegemonia dominante de conhecimentos, saberes, comportamentos impostos aos Africanos. Sigo aproveitando as rachas da pedra dura civilizadora para demonstrar que o poder é uma preocupação central para Africanos interessados na sua expressão cultural. Então, identifico e desmantelo as suposições e práticas coloniais que moldam equivocadamente os termos da Mbira elencando e discutindo as terminologias da Mbira tendo em conta os contextuais originais da sua produção.

\section{TERMINOLOGIAS DA MBIRA NUMA PERSPECTIVA DO NORTE GLOBAL}

A construção das sociedades do continente Africano tem sido acompanhada por preconceitos e estereótipos que se reflectem na historiografia sobre os seus diferentes povos encaminhando equivocadamente o que seria a sua contribuição na história da humanidade. Estes equívocos são de alguma forma vinculada às "grandes narrativas" do Iluminismo, hegelianismo, marxismo etc., que afirmam ser o fundamento último para legitimar a crença no progresso histórico e no poder emancipatório da razão (PELINSKI, 2002, p. 1).

\footnotetext{
Hegel [...] concebeu o Espírito Universal, a razão, movendo-se do Oriente para o Ocidente (HEGEL, 1999). O leste era o passado que estava estagnado; O Ocidente era o presente que desenvolveu o Espírito Universal; e a América branca era o futuro. Ásia formava um estágio inferior do Espírito Universal, a África e o mundo indígena não faziam parte dele, e as mulheres nem eram mencionadas, exceto para falar sobre casamento e família (GROSFOGUEL, 2007, p. 67)9.
}

Para Pelinski (2002) tais teorias implicam uma visão de mundo eurocêntrico, um cânone acadêmico e artístico unidimensional e formas ocultas de dominação patriarcal que sustentam relações racistas, sexistas, homofóbicas e de classe. Assim, as práticas orientais indíge-

8 Mignolo (2007, p. 33)

9 Hegel, en continuidad con el racismo epistémico de los filósofos occidentales que le antecedieron, concebía el Espíritu Universal, la razón, moviéndose de Oriente hacia Occidente (Hegel, 1999). Oriente es el pasado que quedó estancado; Occidente es el presente que desarrolló el Espíritu Universal; y la América blanca es el futuro. Si Asia forma una etapa inferior del Espíritu Universal, África y el mundo indígena no forman parte del mismo, y las mujeres ni siquiera son mencionadas, excepto para hablar del matrimonio y la familia (GROSFOGUEL, 2007, p. 67). 
nas e africanas foram, equivocadamente, quase sempre inferiorizadas, pois no entendimento dos arquitectos da ordem hegemônica global o Espírito Universal e Objetivo de competência e, portanto digno de proteção, nunca havia passado pelo oriente. Em visão de Foktel "Hoje [1788], ainda encontramos, no entanto, muitos povos asiáticos, africanos e americanos, que também sabemos que não fizeram progresso para os milênios em outros ramos da cultura" (FORKEL, 1967, p. 285).

Nesse equivoco, me auxilio do Gómez e Grosfoguel (2007) para destacar que os estudos dos povos africanos e suas práticas culturais ainda envolvem uma reflexão crítica sobre as hierarquias de poder e conhecimento gerado pelo caráter universal, sobretudo ocidental que ocultava e continua ocultando a construção autêntica da História da Humanidade. O período colonial de dominação de poder e soberania de um povo sobre o outro, quase, acabou na África, mas a colonialidade do poder de conhecimentos, saberes, comportamentos global permanece ativa, dominando profundamente o período da construção continental e depreciando o patrimônio histórico imaterial (linguagem, hábitos, costumes, moral, etc) da humanidade.

No contexto de Música de Mbira esta dominação se deu empregando terminologias europeias na nomenclatura do instrumento, como uma tentativa de "civilização". Segundo o etnomusicólogo americano Paul Berliner citando as palavras de etnomusicólogo zimbabuano Dumisani Abraham Maraire, muitas pessoas chamam a Mbira por nomes europeus, com conotação depreciativa, pois foram assim ensinados pelos missionários cristãos, que pretendiam engrandecer os seus instrumentos musicais em detrimento dos africanos. Maraire reagia ao fato de que as pessoas da mesma cultura que apoiaram a educação dos missionários em África referiam-se com regularidade ao seu instrumento (Mbira) de forma etnocêntrica (eurocêntrica), usando designações como "piano de dedo/finger piano", "piano de polegar/thumb piano", ou "piano de mão/"hand piano,"e mostravam-se, pouco interessadas em aprender o seu próprio nome africano (BERLINER, 1978, p. 9) ${ }^{10}$.

O que está explícito nesse contexto é a sedução da cultura europeia que se transformou em uma espécie de molde cultural universal promovido pelos próprios europeus, mas incorporado por africanos colonizados. A meu ver, este contexto denota como a colonialidade sobrevive, soando como uma caixa de ressonância ao colonialismo. Esta ressonância se exibe nos textos, metodologias e dinâmicas de trabalho principalmente acadêmico, bem como nos padrões culturais, na autoestima e aspirações dos sujeitos humanos colonizados.

Este foi um dos tantos exemplos de silenciamento da nomenclatura da Mbira causado pela necessidade de inculcar um pensamento que pudesse persuadir o bárbaro a se transformar em um agente civilizado. Esta transformação no entender do universalismo só podia operar-se em língua portuguesa ou inglesa através de um instrumento ocidental (piano) que pudesse, por hipótese, possuir a mesma configuração ou técnica de execução (digitação) que a Mbira. Assim, o etnomusicólogo e antropólogo social britânico, John Blacking, percebe que "o dedilhado de Kalimba [um protótipo de Mbira] é baseado no dedilhado do piano europeu, embora na kalimba seja usado apenas os polegares" (BLACKING, 1961, p. 28) ${ }^{11}$.

10 All right," He said with a good-natured sarcasm, "that is the way the Christian missions taught me to say 'piano'. Dumisani Maraire was reacting to the fact that people from the same culture that supports missionary education in Africa continually referred to this instrument in ethnocentric terms as "finger piano," thumb piano," or "hand piano," and showed little interest in learning its Africa name (BERLINER, 1978, p. 9).

11 The fingering" has been based on European piano fingering, although only the thumbs are used (BLACKING, 1961, p. 28). 
Essa colocação às vezes nos leva, por suposição, a deduzir que a Mbira é uma cópia do piano. Mas, será que esta constatação é verdadeira? A Mbira é mesmo uma cópia do piano? Vejamos. A invenção do piano é creditada ao italiano Bartolomeo Cristofori (1655-1731, Veneza), mas há outros que contribuíram para o que tornou-se o piano que conhecemos hoje. Ninguém realmente sabe quando o piano foi inventado, mas de acordo com alguns estudiosos, a família Médici, já tinha um piano, aproximadamente, em 1700. Os estudos revelam que, aos 33 anos (em 1688), Cristofori atraiu a atenção de Ferdinando de Médici, o qual o contratou para ajudá-lo a manter os instrumentos de sua vasta coleção, além de tentar inventar alguns novos. "Arpicembalo" era um instrumento que parecia-se com o cravo. A data de sua invenção é considerada como algo entre 1698 e 1699, mas Cristofori poderia estar traba1hando no instrumento desde 1694. Contudo, ele só foi apresentado ao público em 1709 como pianoforte e mais tarde foi abreviado para "piano" ${ }^{12}$ ", conforme a figura 2 (STONE, 2015).

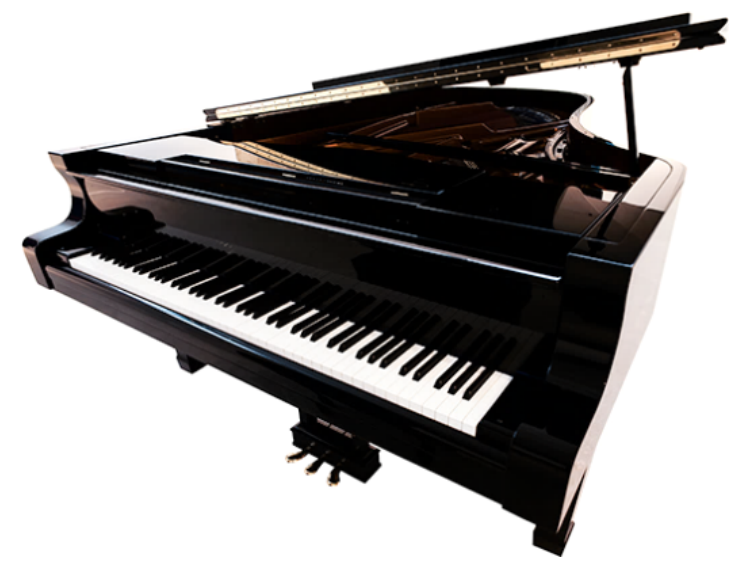

Figura 2: Piano (FRITZDOBBERT, 2017).

A figura 2 revela que a fabricação do piano está muito vinculada ao início da Modernidade que, para autoras como Delgado (2007, p. 199) e Flórez (2007, p. 254), está associada a grandes eventos da história da Europa: a Revolução Francesa, o Iluminismo, a Revolução Industrial, [o progresso, a racionalização] e os seus primórdios estão localizados nos séculos XVIII e XIX. Contudo na tese de Enrique Dussel (2005, p. 29-30) a Modernidade nasce realmente em 1492. Sua real superação foi a incorporação de seu caráter emancipador racional europeu entendido como novo projeto mundial de libertação político, econômico, ecológico, erótico, pedagógico, religioso, etc.

$\mathrm{Na}$ percepção deste filósofo argentino radicado, há dois conceitos de Modernidade. $\mathrm{O}$ primeiro deles é eurocêntrico, provinciano e regional, no qual a modernidade é uma emancipação, uma saída da imaturidade por um esforço da razão como processo crítico, que proporciona a humanidade um novo desenvolvimento do ser humano. A segunda visão da Modernidade, num sentido mundial, consistiria em definir como determinação fundamental do mundo moderno o fato de ser (seus Estados, exércitos, economia, filosofia, etc.) centro da História Mundial (DUSSEL, 2005, p. 27).

O filósofo apresenta uma imagem controversa deste movimento destacando, por um lado que se a Modernidade tem um núcleo racional forte, como saída da humanidade de um estado de imaturidade regional, provinciana, não planetária, por outro, essa mesma Moder-

12 Devo ressaltar que ainda chama-se pianoforte em alguns países como na Itália. Mas, "Piano" é uma abreviação que virou normativa em algumas línguas como inglês e português. 
nidade realiza um processo irracional que se oculta a seus próprios olhos. Ou seja, a Modernidade é justificativa de uma práxis irracional de violência (DUSSEL, 2005, p. 29). Em vista disso, o (etno)musicólogo Philip Vilas Bohman compreende que

O modernismo era o ingresso para a entrada no Ocidente, mas era um ingresso com um preço alto: era necessário adotar a história européia como se fosse sua, desempenhando o papel que lhe foi atribuído no estágio de fin-de-siecle. Os bilhetes que permitiriam uma entrada na esfera pública do modernismo estavam à venda em todos os lugares, [...] Comprar ingressos significava aceitar o papel do exótico atribuído, não apenas concordando, mas também atuando [como exótico] (BOHMAN, 2002, p. 15$)^{13}$.

Contudo, a Mbira, por sua vez, teve origem há mais de 1500 anos na tribo Zezuru, pertencente a etnia dos Vashona ${ }^{14}$, 'grupo dos falantes de Bantu que vive entre rios Zambeze e Limpopo $^{15}$ no Zimbabwe e em uma parte de Moçambique e Zâmbia (BERLINER, 1978, p. 18) ${ }^{16}$.

As evidências arqueológicas e históricas pontuam o fato que a Mbira era um instrumento antigo entre o povo Vashona. Os arqueólogos descobriram vários exemplos das partes de Mbira nas ruínas de Inyanga e nas ruínas próximas a Niekerk no noroeste de Zimbabwe. Uma data estimada dessa descoberta seria entre 1500-1800 A.D ${ }^{17}$. Também tenho visto [afirma Berliner (1978)] Mbiras que foram encontradas em alguns lugares em Karanga próximo da reconhecida ruína de Zimbabwe perto da Fort Victoria na zona sul do país (BERLINER, 1978, p. 28 grifo do autor) ${ }^{18}$.

Este etnomusicólogo (p. 29) descreve que "em 1865, Charles e David Livingstone publicaram o primeiro desenho de Mbira". Mas, também existem evidências encontradas em diários de campo dos primeiros europeus que dão indicações da existência da Mbira entre os Vashona antes do aparecimento do material documentado sobre este instrumento. Assim,

Os diários dos primeiros europeus e aventureiros no sul de África claramente indicam que os Vashona tinham ferreiros altamente habilitados e que a Mbira era um instrumento musical bem estabelecido entre os Vashona pelo menos no século XVI. Além disso, também é sabido que a Mbira era um instrumento musical importante entre os Vashona muito antes da primeira documentação impressa (BERLINER, 1978, p. 2) ${ }^{19}$.

13 Modernism was the ticket for entry into the West, but it was a ticket with a high price: It required adopting European history as one's own, playing the role assigned one on the fin-de-siecle stage. The tickets that would allow one entry to modernism's public sphere were on sale everywhere, [...] Buying tickets meant accepting the role of the exotic that had been assigned, not just acquiescing but also performing (BOHMAN, 2002, p. 15).

14 Os seus dialectos básicos dos Vashona incluem Karanga, Zezuru, Korekore, Manyika, Vandau e Kalanga (BERLINER, 1978). 15 O rio Limpopo tem um comprimento de cerca de $1600 \mathrm{~km}$ (certas fontes referem $1770 \mathrm{~km}$ ) e a sua bacia hidrográfica cobre cerca de $415000 \mathrm{~km}^{2}$. Este rio é o segundo maior rio do sudeste da África e serve de fronteira entre a África do Sul, Botswana, Zimbabwe, Moçambique, desaguando no Oceano Índico.

16 "The name shona refers to a group of bantu-speaking people who live between Zambezi and Limpopo rivers in Zimbabwe and in part of Mozambique and Zambia" (BERLINER, 1978, p. 18).

17 A.D. abrevia Anno Domini, uma expressão latim que significa "ano do Senhor". É utilizada para marcar os anos seguintes ao ano 1 do calendário mais comumente usado no Ocidente, designado como "Era Cristã" ou, ainda, como "Era Comum".

18 "Archaeological and historical evidence points to the fact that the mbira was an ancient instrument among the shona people. Archaeologists have discovered several examples of mbira parts at ruins of Inyanga and the nearby Niekerk ruins in north-eastern Zimbabwe. An estimate of the date of such finds is 1500-1800 a.d. I have also seen mbira that were found at the karanga sites close to the better known Zimbabwe ruins near Fort Victoria in the southern part of the country" (BERLINER, 1978 , p. 28, grifo do autor).

19 " [...] the diaries of the first European missionaries and adventures in Southern Africa clearly indicate that the shona were highly skilled blacksmiths and that the mbira was well-established musical instruments among the shona at least by the sixteenth century. Moreover, it is most likely that the mbira was an important musical instrument among the shona long before its first printed documentation" (BERLINER, 1978, p. 29). 
Em sua contribuição, o etnólogo e musicólogo austríaco de Viena demonstrou que a Mbira parece ter sido inventada duas vezes na África: a primeira Mbira revestida de madeira ou bambu foi encontrada na costa oeste da África há cerca de 3000 anos (figura 3) e a segunda (lamelofone) revestida de metal foi encontrada no vale do rio Zambeze há cerca de 1300 anos, conforme a figura 4 (KUBIK, 1998, tradução minha $)^{20}$. Em outra pesquisa realizada em Angola, no Distrito do Cuando-Cubango, entre Agosto e Dezembro de 1965 este etnógrafo-musicólogo evidenciou que os materiais usados, inicialmente, na fabricação da Mbira eram de origem vegetal: palmeira de ráfia, madeira, bambu e outros (KUBIK, 2002).
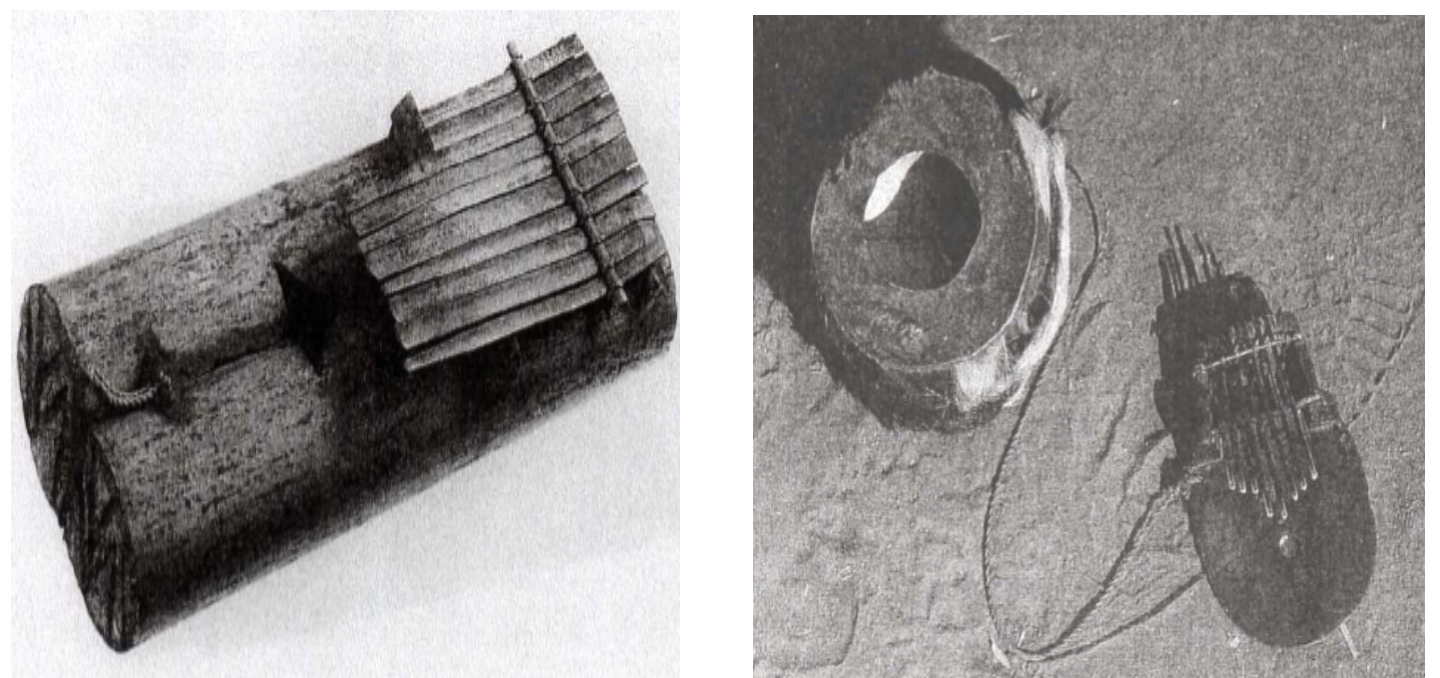

Figura 3: Mbira revestida de bambu (KUBIK, 1998). Figura 4: Mbira revestida de metal (KUBIK, 1998).

A literatura apresentada direciona-me a duas constatações: Primeiro, a fabricação mais antiga da Mbira era de origem vegetal, o que me leva a concluir que ela antecede a idade de ferro (Metalurgia) na África. Algumas sociedades da África subsaariana (ao sul do deserto do Saara) viviam a chamada Idade do Ferro entre os séculos V e II A.C.. Naquela ocasião, elas aprenderam a manipular o ferro e forjaram armas e utensílios diversos com o metal. Uma das culturas que constituiu as civilizações da Antiguidade no continente africano foi a Nok, civilização que se desenvolveu na região da atual Nigéria, entre os anos 100 e 300 a.C. (CARVALHO, 2020). A literatura destaca que a Cultura Nok foi a primeira sociedade que refinava ferro mediante fundição na África ocidental, mas, logo depois, o seu uso estendeu-se para o extremo sul do continente.

Segundo, a descoberta da Mbira está, por um lado, muito vinculada a uma abordagem continental das etnias e tribos africanas que data um período antes da chegada dos europeus na África por volta do século XV. Isto pressupõe um período que antecede o processo da divisão das relações territoriais entre as etnias africanas, causada pela conferência de Berlim (1884-1885) e dos interesses das nações imperialistas do século XIX tais como a Inglaterra, França, Alemanha, Portugal, Bélgica, Espanha, Holanda, Itália, entre outras (CURADO, 2018) que violaram em várias ocasiões a integridade territorial e tradicional dos Estados africanos que compartilham fronteiras comuns.

20 The mbira appears to have been invented twice in Africa: a wood or bamboo-tined instrument appeared on the west coast of Africa about 3,000 years ago, and metal-tined lamellophones appeared in the Zambezi River valley around 1,300 years ago (KUBIK, 1998). 
Especificamente, o colonialismo resultou em rupturas e transformações significativas nas esferas política, econômica e artística, afetando pessoas em praticamente todos os lugares, com implicações importantes para as tradições musicais. Dentro desse campo da modernidade, pessoas de todo o mundo começaram a redefinir suas identidades pessoais e culturais em relação às forças globais (MCCOLLUM; HEBERT, 2014, p. 5) ${ }^{21}$.

Esta violação da integridade africana permitiu a formação do que hoje é chamado 54 países africanos ${ }^{22}$ (Moçambique, Zimbabwe, África do Sul, Malawi, Cabo Verde, Eswatini, Zâmbia, Tanzânia, Angola, Kenya, Togo, Gana, Nigéria, Namíbia, Guiné Bissau, Etiópia entre outros) o que faz com que os Vashona, por exemplo, estejam em miniatura numa parte de Moçambique, Zimbabwe e Zâmbia, os Vatsonga em Moçambique e África de Sul, dificultando a luta pela sua identidade cultural e abordagem continental integrá, emergindo novas formas de pensamento que travam entre si e com as formas hegemônicas uma luta intensa para se tornarem prevalentes.

Portanto, o período estimado em relação à descoberta do piano, o tipo de eventos que se relaciona com o seu surgimento (modernidade, iluminismo, revolução francesa e industrial ), o material usado na sua fabricação, o formato do instrumento, o número e formato de teclas, o processo de afinação, até mesmo a técnica de execução não legitima-nos a considerar a $M b i$ ra como piano de mão, de dedo ou de polegar ${ }^{23}$. Não faz sentido reduzir a Mbira a "piano de qualquer coisa", pois isso se designa manutenção das desigualdades e o racismo. Parece um processo natural e inocente, mas julgo que nunca foi, porque "sempre que a cultura dominante pretende adotar elementos ou padrões culturais das minorias, ela o faz sem reconhecer as condições históricas e sociais desses grupos e acaba sustentando as diferenças e consolidando relações de poder desiguais" (WILLIAM, 2019, p. 94).

Quando um elemento cultural (nome, símbolo, objeto, povo, traço, ginga, instrumento, repertório, costume, comida, etc.) é retirado de seu contexto original, assume outros significados diversos ou contraditórios à sua originalidade. Ele é submetido a uma dominação sociocultural passando a ser descaracterizado e desvalorizado ao ponto de aniquilar seu direito de existência tradicional, possibilitando um processo de exclusão que reforça a sua marginalização e gera uma estrutura racista que não permite seu acesso e visibilidade.

Não reconhecer a humanidade do outro, não só promove massacre, é desumano, então me junto ao musicólogo americano, Gary Tomlinson, pois já não tenho tempo de poder tolerar que o estado bruto da música não pode ser determinado com precisão, chega o absolutismo de que as "Sociedades com o alfabeto podem se aproximar de uma arte musical perfeita; as que não têm devem se mudar para outro lugar ou não devem se mover" (TOMLINSON, 2003, p. 42).

Morrer calado, nunca! Não existem culturas analfabetas, pois nem todas as culturas confinam seus repertórios em gráficos escondidos em manuais ou bibliotecas, mas transmi-

21 Specifically, colonialism resulted in significant disruptions and transformations to the political, economic, and artistic spheres, affecting people virtually everywhere, with important implications for music traditions. Within this realm of modernity, people throughout the world began to redefine their personal and cultural identities in relation to global forces (MCCOLLUM; HEBERT, 2014, p. 5).

22 Excluindo a República Árabe Saaraui Democrática

23 O tamanho deste texto não me permite abordar a afinação e técnica de execução, apesar de reconhecer que estes campos iriam clarificar as diferenças do piano e da Mbira. 
tem e ampliam e reverbam seus saberes em outros ambientes de memória significativa. Sigo sustentando a inércia de líderes africanos - Nelson Rolihlahla Mandela, Kwame Nkrumah, Haile Selassie, Samora Moisés Machel, Eduardo Chivambo Mondlane, António Agostinho Neto, Thomas Sankara, Patrice Émery Lumumba, Kenneth David Kaunda, Julius Kambarage Nyerere, Robert Gabriel Mugabe, etc. - que mesmo diante de humilhação e violência submetidos cotidianamente na escola, no trabalho, no hospital, na justiça, etc. sempre demonstraram sua indignação ou tomaram atitudes contra a surdez da linha superior, pois compreendiam que "desconstruir é uma condição básica para alcançar uma sociedade mais justa e promover uma cultura de inclusão" (WILLIAM, 2019, p. 92).

Já basta o pressuposto de que os instrumentos musicais Africanos estão apenas de forma rudimentar e primitiva e que devem sofrer uma direcção gradual e especial para o presente universal "ocidental". Essa dimensão gradual se alinha às perspectivas de colonialidade do saber que pauta pela repressão de outras formas de produção de conhecimento não europeias, tendendo a negar o legado intelectual e histórico de outros povos, como os indígenas e africanos, reduzindo-os a categorias vazias e preconceituosas, como primitivos e irracionais por pertencerem a "outra raça" (QUIJANO, 2007).

No campo da música, posso destacar o paradigma colonial que condicionou desde, a concepção do campo, um tipo de musicologia que atendia principalmente a obras registradas por parâmetros de notação musical ocidental que parte fundamentalmente da Europa e se projetam para o resto do mundo como único conhecimento digno de proteção e reconhecimento pelos "outros". É preciso desconstruir essa realidade e buscar estratégias que reajam fortemente aos epistemicídios musicais (nomes da Mbira), pois eles "ao estabelecer profundas mortes de conhecimentos, saberes e simbolismos, também corroboram para a consolidação e a permanência de grandes males que adoecem a humanidade: racismo, xenofobia, machismo, homofobia, miséria, fome, falta de moradia, entre outros" (QUEIROZ, 2017b, p. 100).

Julgo que é didático pedagógico e científico coletar e analisar terminologias a partir do olhar do seu percusor, origem, história do que procurar fazer ligações que valorizam uma determinada cultura deslocada. Trata-se de um princípio fundamental que deve ser observado para manter o título de propriedade dos direitos sobre a sua criação, evitando os assassinatos simbólicos das terminologias dos instrumentos musicais e outros dispositivos africanos. "Ao matar formas de pensar, formas de sentir, formas de ser e estar no mundo, formas de fazer e sentir músicas, se assassina sujeitos. E esses assassinatos simbólicos geram intolerâncias e massacres que resultam, inclusive, em assassinatos físicos" (QUEIROZ, 2017b, p. 107).

Concordo que muitos manuais que usam essas terminologias eurocêntricas ajudaram bastante na divulgação da Mbira, OBRIGADO!, mas para além de perpetuar epistimicídios, eles perderam a seiva que contém os princípios nutritivos que circulam entre os fazedores da Música de Mbira, por isso as folhas da genealogia dos Vachayi va Timbira murcharam, perdendo a capacidade de produção do oxigénio para a sobrevivência do próprio planeta que procura pela Música de Mbira. Assim, o que proponho pensar como "termos em perspectiva global" são enunciações equivocadas, se não mentirosas, que até os dias de hoje sustentam, esforçadamente, sistemas de poder social sobre as dimensões do ser e saberes africanos. ISSO MERECE UMA DECOLONIZAÇÃO! 
Quero deixar claro que a decolonização das terminologias da Mbira que está sendo proposta neste texto não implica um braço de ferro contra a ciência moderna do Ocidente. Mas é necessário analisar e refletir mais afundo em relação a essa epistemologia, não porque ela deve ser negada ou superada por algo melhor, mas criar uma extensão do campo de visibilidade científica baseada numa conjunção epistêmica de vários domínios (emoção, tradição, senso comum, ancestralidade, etc.). Trata-se, portanto, de "Um pensamento integrativo no qual a ciência ocidental pode "se vincular" a outras formas de produção de conhecimento, com a esperança de que a ciência e educação deixem de ser aliadas do capitalismo [...]" (GÓMEZ, 2007, p. 90) ${ }^{24}$. Essas ações decoloniais, a meu ver, no campo do saberes da Mbira são giros conceituais do mundo e problematizações que confrontam os limites do que é apresentado, mentirosamente, como princípio único da linha férrea a salutar.

Nesse sentido, as terminologias da Mbira na perspectiva do norte global mostram que há rachas, portanto lógicas da colonialidade, que merecem uma intervenção realmente "civilizatória". Tal civilização implica trabalhar dentro dos problemas de cada sociedade, lidando com as suas potencialidades e ameaças com vista a produzir mudanças fundamentais nas relações de ser, saber, poder, e, sobretudo na(s) visõe(s) de mundo. Portanto, uso o termo decolonização como um repensar das estruturas nominais que sobraram do período colonial formal. Assim, para nomear as terminologias da Mbira, como apresento no próximo item, destaco os sujeitos, práticas, situações, espaços e épocas contextuais que expandem um campo de visibilidade aberto para uma ciência baseada em um pensamento integrativo das culturas para a construção da humanidade.

\title{
TERMINOLOGIAS DA MBIRA E SEUS CONTEXTOS SOCIOCULTURAIS NA ÁFRICA
}

A cultura é uma forma de representação simbólica que transmite e expande indelevelmente os costumes, linguagem, práticas identitárias e liberadoras das mentes de um povo. Para o nacionalista Africano Amílcar Cabral, engenheiro agrônomo e escritor guinness, considerado como o ideólogo da independência de Cabo Verde e da Guiné-Bissau:

\begin{abstract}
A cultura provou ser o próprio fundamento do movimento de libertação. Somente as sociedades que preservam suas culturas são capazes de se mobilizar, organizar e lutar contra a dominação estrangeira. Quaisquer que sejam as formas ideológicas ou idealistas, a cultura é essencial para o processo histórico. [Ela] tem o poder de preparar e tornar férteis os fatores que garantem a continuidade histórica e determinam as chances de uma sociedade progredir (ou regredir) (CABRAL, 1973, p. 16) ${ }^{25}$.
\end{abstract}

Esta proposição é fundamentada pelo general nigeriano Mathew Okikiọla Arẹmu Olusegun Obasanjo que em suas palavras afirma: "acredito que a sua cultura também faz parte da sua identidade. Isso é algo que você nunca deve permitir que seja tirado de você. Que inclui seu nome, sua comida, sua dança e seu vestuário" (CGTN Africa, 2014, tradução minha) ${ }^{26}$. Estes atributos

24 Un pensamiento integrativo en el que la ciencia occidental pueda "enlazarse" con otras formas de producción de conocimientos, con la esperanza de que la ciencia y la educación dejen de ser aliados del capitalismo posfordista (GÓMEZ, 2007, p. 90).

25 Culture has proved to be the very foundation of the liberation movement. Only societies which preserve their cultures are able to mobilize and organize themselves and fight against foreign domination. Whatever ideological or idealistic forms it takes, culture is essential to the historical process. It has the power to prepare and make fertile those factors that ensure historical continuity and determine a society's chances of progressing (or regressing) (CABRAL, 1973, p. 16).

$26 \mathrm{I}$ believe that your culture is also part of your identity. That is something that you should never allow to be taken away from you. Which includes your name, your food, your dance and your dress (CGTN AFRICA, 2014). 
foram, igualmente, especificados nos Melhores Discursos de Samora Moisés Machel, um líder revolucionário de inspiração socialista, militar moçambicano que liderou a guerra da independência e foi eleito primeiro presidente de Moçambique independente. Em seu monólogo responsorial articula:

\begin{abstract}
Vocês sabem quais são as características africanas? usar pele e tanga, capulana; atravessar um pau na mão atrás do rebanho, cabritos, gado; magrinho com costelas muito facilmente de contar uma por uma; ferida nos pés, nas pernas com uma folha de cajueiro a tapar a ferida que vai gotejando; matequenha ${ }^{27}$ nos pés; este é africano, são as características do africano, ouviram, ouviram? Então quando vem os turistas procuram este Africano que está vestido desta maneira, porque este é o real Africa; agora encontra o Marcelino vestido de balalaica, casaco, já não é africano este, não tiram fotografias [...] (HelB M, 2019).
\end{abstract}

A preocupação de valorizar as características africanas foi atendida flexivelmente nos Dez Momentos para entender Jonas Malheiro Savimbi, um político-guerrilheiro angolano e líder da $\mathrm{UNITA}^{28}$. Ele entende que

\begin{abstract}
A Negritude para nós é uma salvaguarda dos nossos valores culturais, nós temos que aceitar que outras civilizações têm culturas umas "mais fortes" [diferentes] do que as nossas. Nós temos que aceitar que há outros valores que não sejam os nossos, por isso mesmo temos de ordenar o nosso ambiente, a nossa mente, a nossa casa para podermos receber os valores culturais de outras civilizações sem perdermos a nossa base de sustentação. E essa base está na Negritude e na Negritude entram também os brancos, entram também os mestiços, entram também os negros. Nós temos que ter um estudo para que em contato com outras civilizações não desapareçamos (MWANGOLE TV, 2020).
\end{abstract}

Nas colocações dos quatro líderes africanos não encontrei nenhum traço de extermínio cultural. Sendo mais claro "destituir valores da cultura, destruir referências, desprover de identidades, apagar os sentidos, esvaziar de significados são armas do colonizador" (WILLIAM, 2019, p. 88-89). Tendo como foco estas intimações argumentativas e transformadoras de paradigmas de poderes e privilégios coloniais sobre a realidade cultural Africana, para nomear cada tipo de Mbira num contexto Moçambicano vários pesquisadores se atém aos nomes: Mbira Nhare ou dzaVadzimu, dzaVandau, Nyunganyunga, Nyonganyonga, Kalimba, karimba, Urimba, Malimba, Marimba, Ndhondhoza, Dzava-Nyungué Moto m'djindja, Nsansi/Sansi, Xitata dentre outros. Denominações como Nhare, Njari ou dzaVadzimu, dzaVandau, Nyunganyunga, Matepe/ Madhebhe dza mhondoro /Hera, Kwanangoma, Kalimba, Karimba são muito usadas em Zimbabwe, podendo-se também encontrar designações como Ringa, Rissange, Quisanje, Likembe, Kisanji, Ocisanji, Cisanzi em Angola; Kalimba, Ndimba, Njari, Njari huru, Ndandi, Kankobele em Zâmbia; Ilimba, Marimba Madogo em Tanzânia; Likembe em Congo; Kadongo em Uganda; Thishanji e Kangombyo em Namíbia; Timbrh em Camarões; Agidigbo em Nigéria Sansi, Nyonganyonga em Malawi (BLACKING, 1961; BERLINER, 1978, DUARTE, 1980; DIAS, 1986; WILLIAMS, 2000; KUBIK, 2002, 2017; GUMBORESHUMBA, 2009; SILAMBO, 2012, 2018; TRACEY, 1961, 1972, 1974, 1989).

É tanta terminologia, diversidade e complexidade para único instrumento musical. Mas, o que essas terminologias valem para os sujeitos, práticas, situações, espaços e épocas africanas? Serão apenas denominações aleatórias? De que maneira essas terminologias se

27 Insecto frequente em regiões quentes, que pode-se introduzir na pele provocando ulcerações. 28 União Nacional para a Independência Total de Angola. 
articulam com as subjetividades individuais e coletivas? Como e por que compreender essas terminologias como processos identitários africanos na colonialidade global? Para responder estes questionamentos vale a pena estudar algumas terminologias de modo particular. Nessa perspectiva, os termos da cultura africana e sua própria sabedoria, inspiram a produção deste texto como uma ação reacionária contra nomes que me foram apresentados na literatura, que como tal, os modelei em meu corpo e os quer devolver de forma transformada para os outros como um processo digestivo.

\section{MBIRA DZAVADZIMU (DZEMIDZIMU)}

A Mbira dzaVadzimu (figura 5) é tocada principalmente para auxiliar nas cerimônias religiosas dos espíritos ancestrais (Vadzimu). Ela está intimamente relacionada a Matepe, Hera ou Madhebhe, que também são tocadas para Vadzimu pelos povos Vakorekore, Vasena ou Vatonga de Zimbabwe e pelos Vatavara e Vanyungwé de Moçambique (TRACEY, 1972).

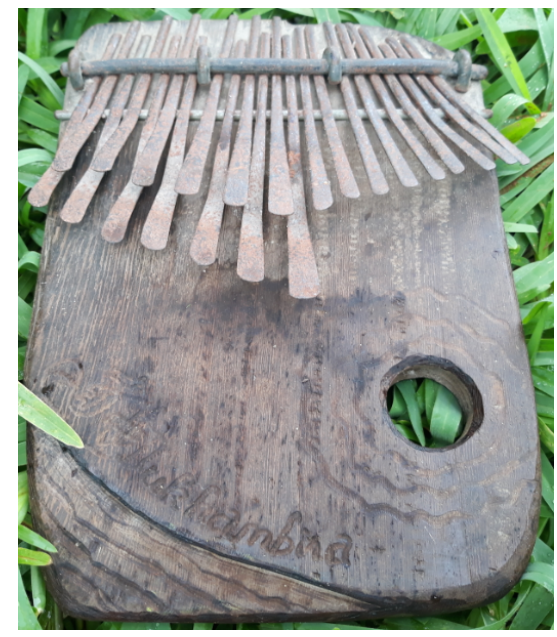

Figura 5 - Mbira dzaVadzimu (Mukhambira, Outubro, 2011).

A Mbira dzaVadzimu embora por vezes usada para entretenimento, era mais frequente ser usada em cerimónias de evocação dos espíritos ancestrais dos Vashona designadas mapi$r a^{29}($ singular bira $)$.

A bira é uma cerimônia formal que dura toda a noite, na qual os membros da família se reúnem para pedir ajuda a um espírito ancestral comum. Durante a cerimônia, o espírito discerne a causa da doença ou infortúnio através da consulta aos aflitos. A família serve bebidas do ritual, especialmente fabricada em homenagem aos antepassados, e convida um conjunto de executantes de Mbira para fornecer a música da noite (BERLINER, 1978, p. 187) ${ }^{30}$.

Assim, a dzaVadzimu funciona como uma linguagem comum entre os espíritos Vashona mortos e os seus descendentes vivos, daí a proveniência do seu nome Mbira dzaVadzimu, que significa Mbira dos "dza" espíritos ancestrais "Vadzimu". No continente africano a Mbira faz parte da vida cotidiana, em situações religiosa, social, política, artística e econômica, sendo

29 Mapira é plural de bira, uma cerimônia religiosa e tradicional dos Vashona na qual se executa a música de Mbira. Há uma semelhança entre as palavras "bira e Mbira", podendo por presunção, concluir-se que ambas têm origem do verbo Kupira que significa uma ritual de oferta" (BERLINER, 1978, p. 187).

30 The bira is a formal, all-night ceremony in which family members come together to call upon a common ancestor for help. During the ceremony a spirit medium discerns the cause of the illness or misfortune through consultation with the afflicted. The family serves ritual beer, especially brewed in honor of ancestors, and sponsors an mbira ensemble to provide the evening's music (BERLINER, 1978, p. 187). 
também vital que esteja conectada à relação da ancestralidade e com os seus descendentes que permanecem na terra (lugar e tempo).

A Mbira é considerado sagrado pelo seu papel crucial nas cerimônias tradicionais dos Vazezuru e como tal para os africanos este instrumento também fala, ela se comunica. A música desse instrumento une o mundo dos vivos e o mundo dos espíritos, atraindo os espíritos mortos. Ela envolve os participantes na cerimônia para meditar, estimulando a sua participação incansável na dança, com palmas e cantos que acompanham a música durante a noite (BERLINER, 1978, p. 190). Para Flora Pereira da Silva:

Ajustada para ressonar e para criar notas emocionais, a Mbira dzaVadzimu mais do que um instrumento é um artefato espiritual, sendo utilizada como forma de comunicação com os antepassados na cultura tradicional Africana tanto em cerimônias religiosas como em encontros sociais; o seu som é considerado sagrado, representando a conexão com os espíritos ancestrais através da música (SILVA, s. $\mathrm{d}^{31}$ ).

A Mbira age, nesta prática tradicional, como um repositório da espiritualidade dos Vashona que é atraído para a dimensão dos vivos, onde o tempo sagrado é assim renovado à medida que essa música interage profundamente com os participantes. Este tipo de Mbira representa um povo, uma tradição, uma forma de relacionamento com a espiritualidade o que justifica a tese do etnomusicólogo americano ao referir que a "Mbira não é apenas um instrumento, e sim como uma bíblia [...], um caminho que foi encontrado para rezar" (BERLINER, 1978, p. 190) ${ }^{32}$. A Mbira Dzavadzimu pode ser, assim, usado em performances musicais especiais que simbolizam a essência, presença ou autoridade ancestral ou outra sobrenatural.

Tal instrumento é então usado exclusivamente em contextos de eventos que invocam ou evocam a presença afetiva, intervenção, participação física ou protetora de tais seres ultra-mundanos nos assuntos humanos. [...] Em outras circunstâncias, o som significativo pode ser interpretado como a "voz" da essência sobrenatural que o simboliza (NZEWU, 2007, p. 78) . $^{33}$.

A Mbira dzaVadzimu é comumente relacionada com a Matepe (figura 6) que é também um tipo de Mbira que

está associada aos Vadzimu (espíritos ancestrais) e, em particular, ao espírito tutelar do clã de cada chefe e subchefe, conhecido como Mhondoro (leão). A conexão de Matepe com os ritos do culto aos antepassados envolve qualquer ocasião ritualística como a indicação de um chefe, oração de pedido de chuva (Mukwerera), festas de bebidas tradicionais destinadas a uma pessoa doente ou uma cerimônia de possessão (Svikiro). Nestas ocasiões é desejável que os executantes de Mbira estejam presentes para tocarem músicas contextuais, em homenagem ao Mhondoro em questão (GUMBORESHUMBA, 2009, p. 31$)^{34}$.

31 Este texto não apresenta o ano da publicação.

32 "The mbira is not just an instrument to us. It is like your bible. It is the way in which we can pray to god". (BERLINER, 1978, p. 190).

33 Such an instrument is then exclusively used in event contexts that invoke or evoke the affective presence, intervention, physical or protective participation of such ultra-mundane beings in human affairs. The instrument could at the same time still be used for special musical performances. In other circumstances the significant sound could be interpreted as the "voice" of the supernatural essence it symbolizes (NZEWU, 2007, p. 78).

34 Matepe is associated with the vadzimu (ancestral spirits), and in particular with the clan tutelary spirit of each chiefdom and sub-chiefdom, known as mhondoro (lion). Matepe's connection with the rites of ancestor worship involve any ritual occasion such as the installation of a chief, praying for rain, beer-party for a sick person or a medium's (svikiro) possession ceremony, where it is considered highly desirable that one or more mbira players should be present to play the right songs, in honour of the particular mhondoro concerned (GUMBORESHUMBA, 2009, p. 31). 
Nesse contexto compreendo que o instrumento musical pode ser o símbolo da autoridade política ou religiosa investida em um sujeito como principal governante de uma comunidade.

Como tal, tocar ou fazer soar o instrumento em circunstâncias especiais é invocar a proteção da autoridade política ou religiosa que ele simboliza, demonstrar lealdade ou afirmar um pronunciamento feito pela incorporação humana em exercício de tal autoridade. A presença ou som peculiar do instrumento também pode significar a presença ou movimento de um governo político, por exemplo. Igualmente, o som significativo valida publicamente, em nome do corpo coletivo da comunidade / grupo cultural, tal nomeação, reconhecimento, investidura ou comemoração política ou religiosa (NZEWU, 2007, p. 78) 35 $^{35}$

Hugh Tracey (1969) também afirma que outras designações para este tipo de Mbira são Madhebhe dza Mhondoro / Hera que têm origem na área de Nyombwe no Distrito de Darwin encontrado no centro de Zimbabwe. A Matepe é descrita como sendo particularmente de um timbre agradável e seu alcance abrange cerca de três oitavas.

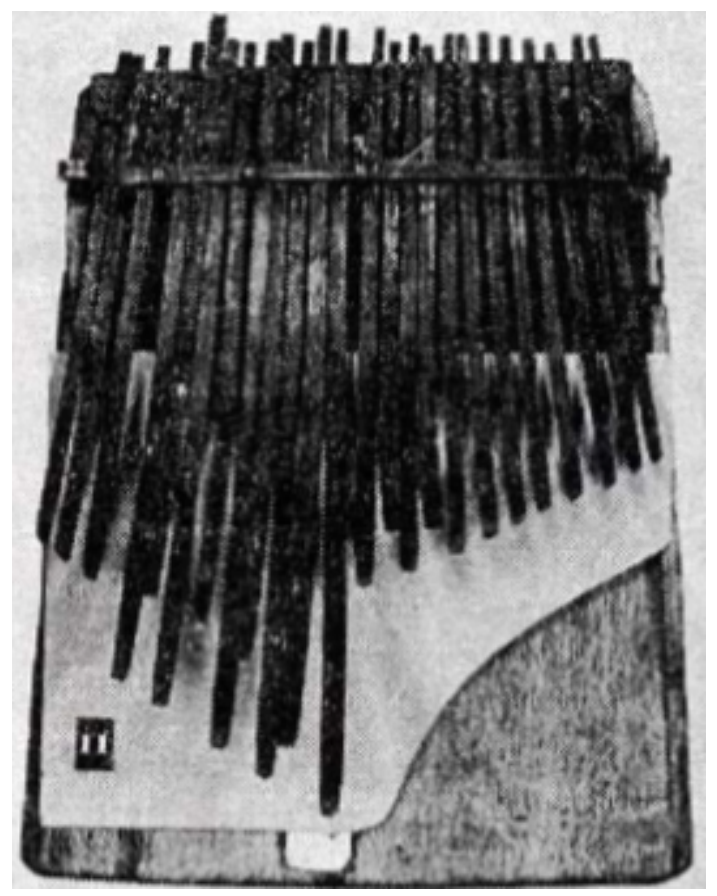

Figura 6 - Madhebhe dzaMhondoro. (H. TRACEY, 1969, p. 87).

Outra Mbira que tem significado ritualístico é a Njari (figura 7), pois ela tem conexão com os midzimu (espíritos ancestrais). Existem três tipos de Njari que são; Njari dzamanjanja, Njari huru e Njari duku. No início dos anos 30, a Njari era a Mbira mais comum em Zimbabwe, no entanto, essa posição agora é ocupada pela Mbira dzaVadzimu. Hugh Tracey (1969, p. 79) reconhece que a Mbira Njari foi trazida para o Zimbábue pela tribo Nyungwé do vale do Zambeze a cerca de 200 a 250 anos atrás. Igualmente, este etnomusicólogo americano (1969, p. 87-91) relata que a história da origem da Mbira Njari está ligada à sub-tribo Njanja

35 As such, to touch or sound the instrument under special circumstances is to invoke the protection of the political or religious authority it symbolizes, or to demonstrate loyalty, or to affirm a pronouncement made by the incumbent human embodiment of such authority. The presence or peculiar sound of the instrument could also signify the presence or movement of a political rulership, for instance. The significant sound equally validates publicly, on behalf of the body collective of the community/culture group, such political or religious appointment, recognition, investiture or commemoration. (NZEWU, 2007, p. 78). 
de Moçambique, na qual entre 150 e 250 anos atrás, um grupo de comerciantes levou-a para o Zimbábue. Como afirma o filho desse americano, "dizem que o nome do clã 'Njanja' é um apelido que indica o som peculiar dos Njari", [pressupondo um nome onomatopaico] (TRACEY, 1961, p. 45).

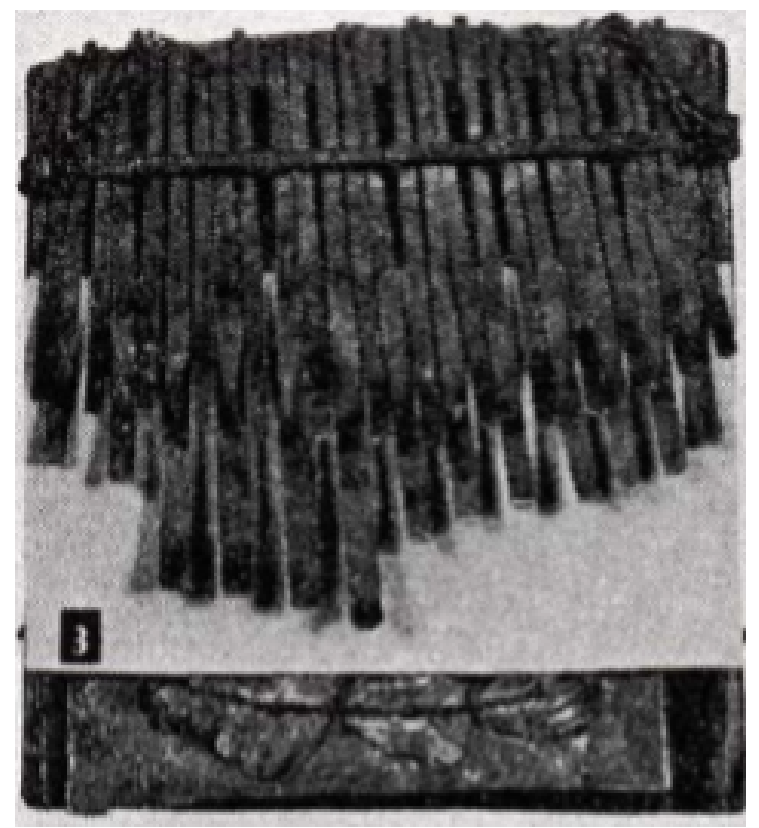

Figura 7 - Mbira Njari (H. TRACEY, 1969, p. 87).

A Mbira, especialmente a dzaVadzimu, é também chamada Nhare. Alguns executantes zimbabuanos de Mbira como Luken Pasipamire e Cosmas Magaya às vezes usavam a palavra Nhare (ferro) para referir indiretamente a Mbira (BERLINER, 1978, p. 239). Este termo era usado como um código que não pudesse ser decodificado pelo público em geral que muitas vezes pressionavam os executantes de Mbira para tocarem nas ruas. Para estes executantes era preciso criar sua linguagem técnica Nhare para manter segredo, dignidade, responsabilidade e sigilo profissional em cerimônias tradicionais da bira face às solicitações espontâneas de atuação nas ruas.

Segundo, "o professor Luka Mukhavele ${ }^{36}$, citando um dos seus professor de Mbira, PePukayi Mudzongwa, a expressão Nhare significa ferro no idioma Shona antigo, podendo, por conjectura, deduzir-se que este tipo de Mbira tenha surgido na fase de transição das lamelas de palmeiras de ráfia ou bambu para as de metal" (SILAMBO, 2012, p. 28). Desta forma, posso concluir que os africanos, tal como europeus e outros, nem sempre dão nomes específicos a cada instrumento, mas referem-se ao material de que esses instrumentos são feitos, bem como ao seu uso e função ${ }^{37}$.

Também existe um tipo de Mbira identificado como Nyonganyonga. Este instrumento encontra-se entre Vasena do distrito de Barué e Gorongosa bem como entre os Vanyanja e outros Vasena que se encontram a partir da parte central abaixo do Rio Zambeze até à zona

36 O professor e etnomusicólogo moçambicano Luka Mukhavele leciona entre outras disciplinas a organologia, acústica e construção dos instrumentos musicais tradicionais e coordena o ateliêr Mukhambira que investigar a música e os instrumentos musicais tradicionais, com enfoque especial para os moçambicanos e africanos, tomando como base vários aspectos inerentes à organologia. Atualmente desenvolve a sua tese de doutorado na Weimar University (Alemanha) com o título "Desafios e Potencialidades dos Instrumentos Musicais Traditionais em Contextos Contemporâneos-Xizambi, Mbira, e Ximbvokombvoko".

37 “[...] o 'uso' refere-se às situações na qual a música é aplicada na ação humana; enquanto a 'função' concerne às razões para a sua aplicação [...]” (MERRIAM, 1964, p. 210) 
Sul de Malawi. Tal Mbira é tocada por quatro dedos (dois polegares e dois indicadores). Os estudos mostram que este tipo de Mbira incluindo Malimba e Sansi são instrumentos musicais tradicionais que eram enterrados com os respectivos executantes de Mbira quando mortos (TRACEY, 1989, p. 129, 131).

Em síntese, a Mbira dzaVadzimu, Matepe (Madhebhe dza Mhondoro/Hera), Njari, Nhare e Nyonganyonga tinham relações com várias situações do cotidiano africano: os espíritos ancestrais, as cerimónias fúnebres, pedido de chuva, cura de doenças, bem como as atribuições onomatopaicas, desenvolvimento de linguagem técnica, permutação do material de fabricação do instrumento, entre outras.

\section{MBIRA NYUNGANYUNGA}

A Mbira Nyunganyunga (figura 8), segundo o etnomusicólogo Luka Mukhavele em conformidade com o seu conterrâneo Sitoe 38 "existia em Moçambique sem este nome, outrora foi levada de Moçambique para Zimbabwe por um zimbabweano de nome Jege A. Tapera" nascido por volta de 1905 na reserva de Mangwendi, 80 quilômetros a leste de Salisbury, no distrito de Murehwa, na Rodésia do sul (Zimbabwe), de pai da etnia Rozvi e mãe da Zezuru (TRACEY, 1961, p. 44). Tapera tinha aproximadamente 25 anos quando decidiu viajar cerca de 320 quilômetros de sua casa em Mangwende (Murehwa) a nordeste de Tete, em Moçambique.

Neste país ele ouviu o Sansi (Chisansi ou Kasansi) conhecido como Karimba, na altura tocada pelo povo local Vasena / Vanyungwé. Ainda em Tete, ele aprendeu duas músicas locais para o instrumento, a Chikunda 1 e Chikunda 2 (TRACEY, 1961, p. 44).

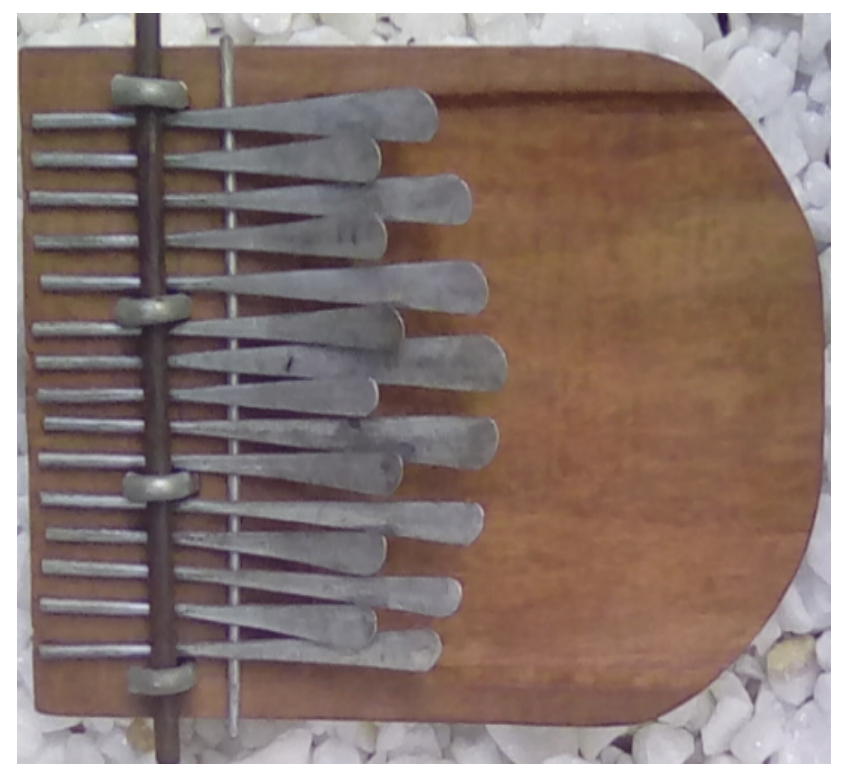

Figura 8 - Mbira Nyunganyunga (MUCAVEL ${ }^{39}$, Janeiro, 2018).

Tapera como outros antes dele, garantiu uma Karimba (Mbira) para si mesmo em Tete e o trouxe para o Zimbábue (TRACEY, 1961, p. 45). Este Muridzi wembira (executante de Mbira-Shona) tendo levado esta Mbira com 13 teclas do povo Vanyungwé, da província de Tete para

38 Pedro Júlio Sitoe é o professor de etnomusicologia na Escola de Comunicação e Artes da Universidade Eduardo Mondlane (UEM), a mais antiga instituição pública de ensino superior em Moçambique no âmbito nacional fundada no dia 21 de Agosto de 1962, pelo Decreto-Lei n ${ }^{\circ} .44530$.

39 Mucavel é um fabricante dos instrumentos musicais tradicionais com enfoque na Mbira. 
o seu país designou-o de Mbira Nyunganyunga tendo em conta a sua etnicidade de origem: os Vanyungwé (SILAMBO, 2012, p. 26). Como explica Andrey Tracey (1961), é razoavelmente correto que a Karimba é uma importação para o Zimbábue, trazida de Moçambique onde se encontra, entre muitos outros, dentro do povo Vanyungwé de Tete. Os Vanyungwé praticam a língua Nyungué ou cinyungwé que é um idioma bantu falado por mais de 400 mil pessoas em Moçambique, principalmente na margem Sul do Rio Zambeze, na província de Tete, desde a fronteira com a Zâmbia até Doa no distrito de Mutarara.

A Mbira, neste contexto, representa uma etnia e língua do centro de Moçambique, o que revela uma das formas aplicada nas sociedades africanas para a atribuição de designações aos instrumentos musicais e que se desdobra para outros dispositivos do cotidiano. Portanto, a Música de Mbira, como qualquer outra "[...] reflete outros aspectos de comportamento, organização, e valores da cultura" (MERRIAM, 1964, p. 247, tradução minha) ${ }^{40}$; ela é uma maneira de entender o mundo e as nossas vivências nele.

A Mbira Nyunganyunga com as suas quinze teclas as vezes era chamada Mbira Kwanangoma (figura 9) em Zimbabwe (GUMBORESHUMBA, 2009, p. 27-28, tradução minha) ${ }^{41}$. A colocação desta etnomusicóloga zimbabuana fundamenta que os nomes dos instrumentos musicais tradicionais africanos às vezes referem-se aos contextos ou locais onde o instrumento (era)é fabricado ou ensinado. Portanto, como afirma o etnomusicólogo Maraire (1991, p. 15), as Mbiras Kwanagoma na sua maioria provinham do colégio de Kwanagoma ${ }^{42}$, no Bulawayo, em Zimbabwe, que por volta de 1966-1967, fabricava e ensinava a execução deste instrumento (SILAMBO, 2012, p. 28).

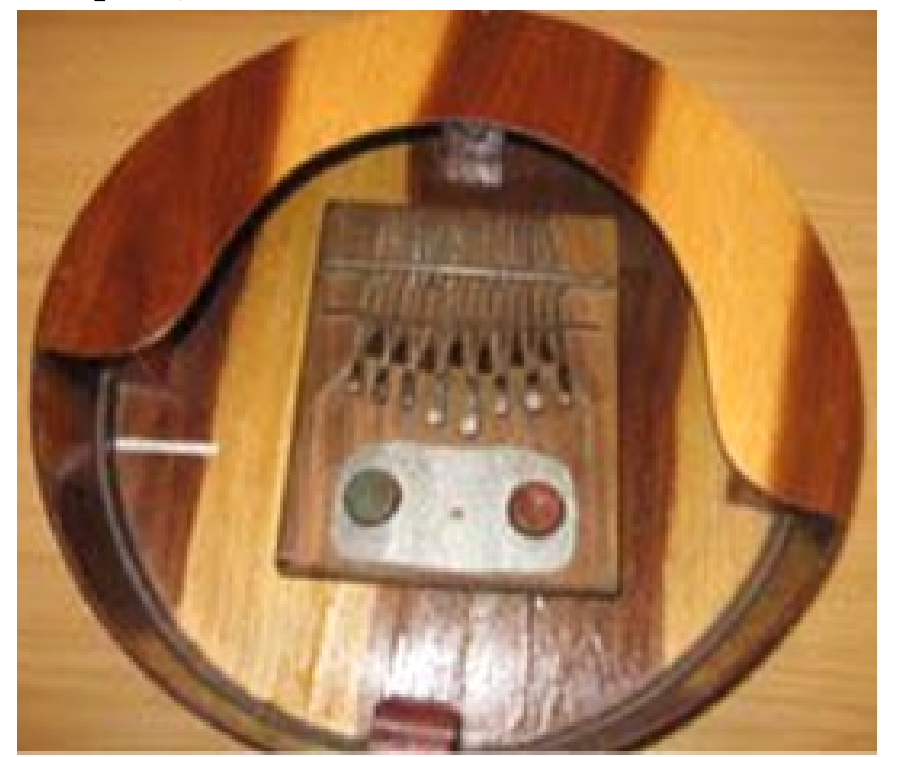

Figura 9: Mbira Kwanongoma (CORTESIA, de ILAM ${ }^{43}$, foto de Elijah Madiba).

No decurso da década 60, a Mbira Nyunganyunga sofreu transformações para se adequar a música dos Vashona de Zimbabwe, ganhando mais duas teclas e passando assim a possuir quinze teclas. Desde a implantação do projeto Mukhambira em 2005, este instrumento voltou

40 "[...] music reflects other cultural behavior, organization, and values" (MERRIAM, 1964, p. 247).

41 The Kwanongoma karimba, sometimes known as Nyunganyunga consists of fifteen keys (GUMBORESHUMBA, 2009, p. 27-28).

42 Este colégio de música foi fundado em 1960 como uma Instituição oficial em que os estudantes africanos aprendiam a música tradicional africana e Europeia com o propósito de desenvolver competências como professor de música.

43 ILAM - International Library of African Music. 
a Moçambique com outras características físicas e acústicas: aumento de número de teclas, novo timbre, novos estilos musicais e contextos de uso, por isso a sua performance, incluindo outros tipos des Mbiras, se dá em contextos variados como feiras, clubes, shows em espaço públicos, "festivais, associações, casas de cultura e pastos, restaurante, bar, entre outros espaços" (SILAMBO, 2018, p. 48). Estes espaços e situações, também, dão sentido a compreensão da Mbira Nyunganyunga apesar da sua origem na etnia dos Vanyungwé.

\section{MBIRA NDHONDHOZA}

Em termos do registro e timbre produzido pelo instrumento, existe Mbira Ndhondhoza (figura 10) inventada pelo Luka Mukhavele. A palavra Kudhondhoza é um termo do idioma xiChangana ${ }^{44}$ usada no Sul de Moçambique que significa produzir sons graves, que os homens (normalmente do sexo masculino) produzem geralmente a partir da adolescência.

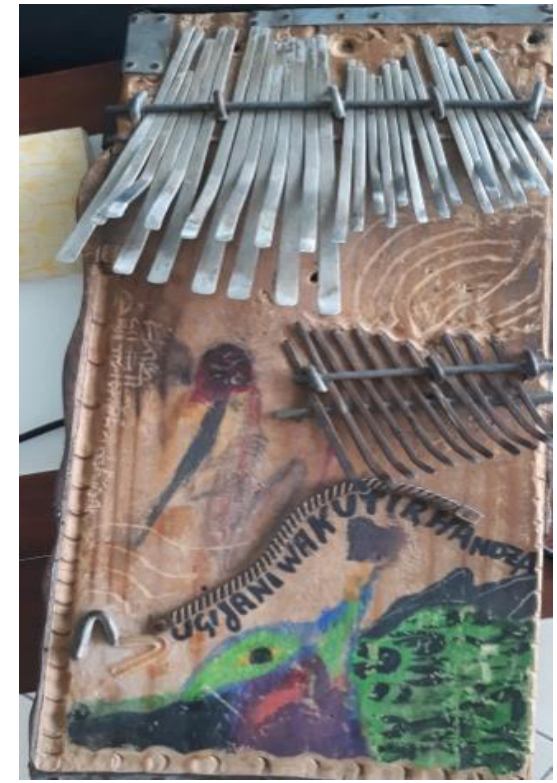

Figura 10 - Mbira Ndhondhoza (MUKHAVELE, Fevereiro, 2019b).

Como o sentido da palavra sugere, a Mbira Ndhondhoza produz sons no registro grave em relação às Mbiras mais comuns (SILAMBO, 2012, p. 25). Este tipo de Mbira tem fortes relações com o seu fabricante, que também possui uma capacidade de produzir sons graves com facilidade tanto na fala como nas suas composições ${ }^{45}$. A Ndhondhoza tem caracteristicas similares que a Mbira Njari, a qual segundo o etnomusicólogo Sul africano Andrey Tracey, é um instrumento independente comparativamente a Kalimba. A Njari apresenta adições de notas de outras maneiras sendo a mais significativa a ampliação da seção de graves do polegar esquerdo. Na Mbira Njari huru ou "big njari", por exemplo, a seção das teclas graves é ampliada e a posição da mão direita aumenta mais cinco notas (TRACEY, 1974, p. 2, tradução minha) ${ }^{46}$. Note também que na Ndhondhoza a secção das teclas agudas é ampliada.

Portanto, a Mbira Ndhondhoza está vinculada ao idioma xiChangana, demonstrando a relação Mbira-instrumentista num processo de personificação em que a música chega ao ins-

44 A língua xiChangana, segundo Ngunga (2004, p. 48), pertence a zona S, grupo Tswa-Ronga S50, no grupo subsidiário S53. Está classificação das línguas moçambicanas é segundo Guthrie (1967-1971) a que aplica o critério geográfico-genealógica. 45 Confira neste link: https://youtu.be/6bjSxjU46J8 (MUKHAVELE, 2019a)

46 The njari is already an independent instrument from the kalimba. makes its additions in its own way, the most significant being the enlargement of the bass section for the left thumb. The njari huru or 'big njari' is just that - the bass section is further enlarged and the right hand rank is extended by five more notes (TRACEY, 1974, p. 2). 
trumentista através do timbre da frequência executada na instrumento. A preocupação com interação entre o corpo humano e a morfologia do instrumento, também tem levando os Vakhandhi va Timbira (fabricante de Mbiras) a moldarem de forma personificada a estrutura do instrumento, canalizando a sua criatividade musical em direções previsíveis em termos do timbre da música. "A personificação do instrumento segundo alguns músicos, [...], indica a natureza íntima do relacionamento entre o executante e a Mbira durante a sua performance" (BERLINER 1978, p. 128, tradução minha) ${ }^{47}$. Evidentemente, esta relação personificada depende do modo como o instrumento musical é usado em criações musicais explorando interativamente a sua qualidade tonal, timbre, bem como efeitos sonoros produzidos simpaticamente quando o instrumento é tocado. Nesse contexto singular, percebe-se que a Mbira é capaz de fazer sugestões musicais ao instrumentista durante a performance, mas que todo processo é subentendido no nome onomatopaico do instrumento.

\section{MBIRA DZAVA-NYUNGUÉ MOTO M'DJINDJA}

A Mbira Dzava-Nyunguê Moto m'djindja (figura 11) é da autoria de um dos maiores exímio fabricante e mobilizador da música em Moçambique, o Mestre Ivan Yohan Mucavel. Como indica o percursor deste tipo de Mbira, a fabricação da primeira Dzava-Nyungue Moto m'djindja foi concluída no dia 23 de Setembro de 2019 no ateliêr Mukhambira situado, atualmente, em Marracuene à $27 \mathrm{~km}$ da cidade de Maputo - um espaço que nos insere diante de sons da natureza, as árvores, os pássaros e outros seres de diferentes espécies. A concepção desta Mbira, como coloca o Mestre, resultou da necessidade de uma implementação de algumas convenções musicais sem que necessariamente perdesse a identidade estrutural e sonora típica do instrumento. Na sua visão, a Mbira Dzava-Nyungué Moto m'djindja vem expandir cada vez mais a técnica de variação de altura de forma oitavada, dando mais flexibilidade integrativa na prática de Jam Sessions entre Nyunganyungas e outros tipos de Mbira.

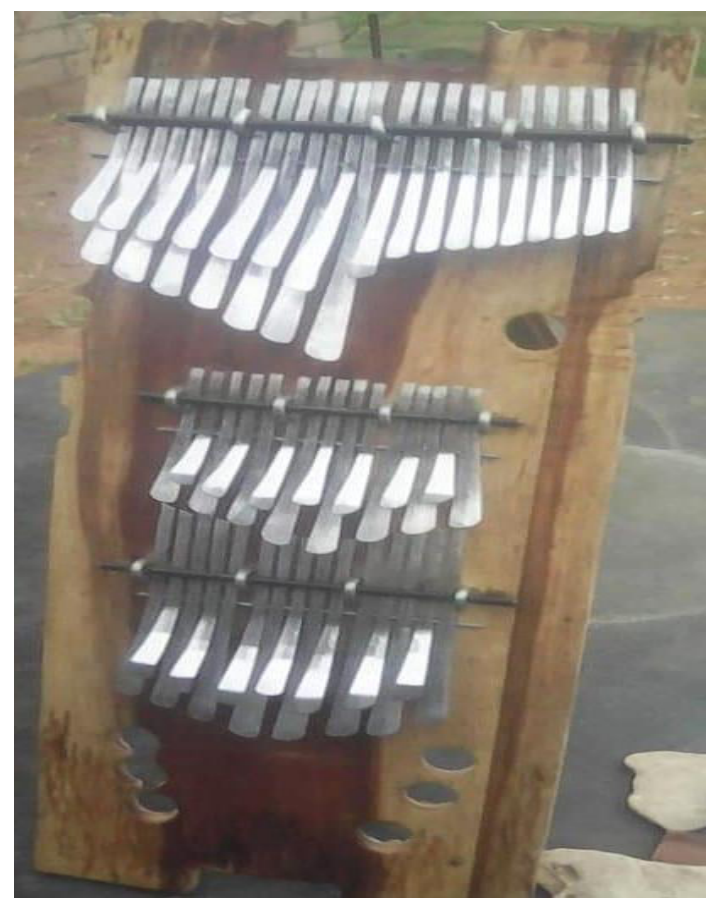

Figura 11 - Mbira Dzava-Nyungué Moto M'djindja (MUCAVEL, Setembro, 2019b).

47 "Personification of the instrument by some musicians, who refer to the music that arises from mbira as its voice, indicates the intimate nature of the relationship between the mbira player and his mbira during the performance" (BERLINER 1978, p. 128). 
Tendo em base uma análise visual desta Mbira compreende-se que esta é composta por dois tipos, a Mbira Nyunganyunga e a dzaVadzimu daí o nome dzava (prefixo contido na palavra dzaVadzimu) e Nyungwé (etnia da onde provém a Nyunganyunga). Quer dizer, trata-se de uma inovação que apesar de ponderar alguns aspectos tradicionais é baseada na tradição da Mbira, mantendo o lema da relação espiritual com ancestralidade e com a etnia dos Vanyungwé, por isso o próprio percursor enfatiza o seguinte:

\begin{abstract}
Quero reafirmar mais uma vez que a pretensão de patenteamento deste instrumento com raizes ancestrais [...] foi muito ponderada [...] e no caso específico esta minha Mbira a qual apelidei-lhe de Mbira "Dzava-Nyungué Moto m'djindja", obedeceu a critérios que têm estritamente a ver com o salvaguardar da propriedade intelectual que foi empreendida na concep̧̧ão desta Mbira em particular (MUCAVEL, 2019a).
\end{abstract}

Como comentou o Luka Mukhavele ${ }^{48}$ a respeito dessa Mbira, ela não pode ser reduzida a um idealismo de entusiasmo e universalismo, pois em suas palavras "Aquela Mbira não pode ser resultado de entusiasmo, mas sim de uma consciência e visão lúcida do nosso potencial, como o único [um dos] instrumento com o poder de nos libertar dessa prisão mental".

Outro aspecto relevante de ser pontuado a respeito da terminologia desta Mbira é o fato de existir o que chamarei, neste texto, de carimbo virtual na nomenclatura do instrumento. Ao falar de carimbo virtual refiro-me às duas últimas expressões usadas neste instrumento "Moto m'djindja" que é o nome artístico e Slogan do Mestre Ivan Mucavel. Nesse sentido, fica evidente que apesar deste fabricante não usar um carimbo sob os seus instrumentos, ele timbra-os através da expressão "Moto m'djindja" que significa para o Mestre "fogo que dificilmente se apaga faça chuva, vento ou sol [...]". Como afirma solenemente o Mestre a respeito deste nome "foi o já falecido Mestre Nharira que me atribuiu. Ele compôs o nome através do adjetivo moto, que em muitas línguas bantu (Swahili) significa fogo, lume, combustão, etc. e acrescentou o Kudjindja de djindjar do tipo forçar, maximizar, aumentar o fogo". A expressão "Moto m'djindja" funciona, não simplesmente como um nome, mas como uma força que atiça a fabricação e a prática da Mbira. Como reitera o Mestre

[...] eu tenho o meu cumprimento muito particular que é o meu slogan né na minha vida de arte [...] que é o Moto m'djindja. Moto m'djindja é aquela expressão que eu uso para inauguração de qualquer debate, de qualquer conversa, então gosto e vou começar mesmo com essa ação que é uma expressão que me incentiva e me dá muito vigor para qualquer atividade que eu tenho que fazer, Moto m'djindja (MUCAVEL, 2019a).

Portanto, a terminologia Dzava-Nyunguê Moto m'djindja apresenta uma reflexão sobre uma inovação baseada na tradição, demonstra a relação entre a Mbira e o fabricante, evidencia uma força que mantém uma dinâmica da prática da Música de Mbira. Contudo, constato que o princípio aplicado por esse fabricante constitui um avanço da ideia apresentada pelo grande virtuoso de Mbira zimbabuano Mubayiwa Bandambira ao reportar que o nome completo de uma das suas Mbiras era naquela ocasião a Mbira Huru dzaVadzimu (BERLINER, 1978, p. 33 - 34) o que também nos remete uma idealização de dois tipos de Mbiras em um só instrumento (tábua ressoadora).

48 Comentário do dia 25 de Setembro de 2019 feito na página do facebook denominada Entusiastas do debate que favorece as Nossas Artes Tradicionais. 


\section{KALIMBA}

Os nomes dos instrumentos musicais tradicionais africanos, também, podem ser determinados pelo seu tamanho. Um dos exemplos é Kalimba ou Karimba (figura 12), sendo outros exemplos da mesma classe e família, o Xikulu (instrumento de teclas maiores que Mbila $^{49}$ ) e Mbira Huru (SILAMBO, 2012, p. 27).

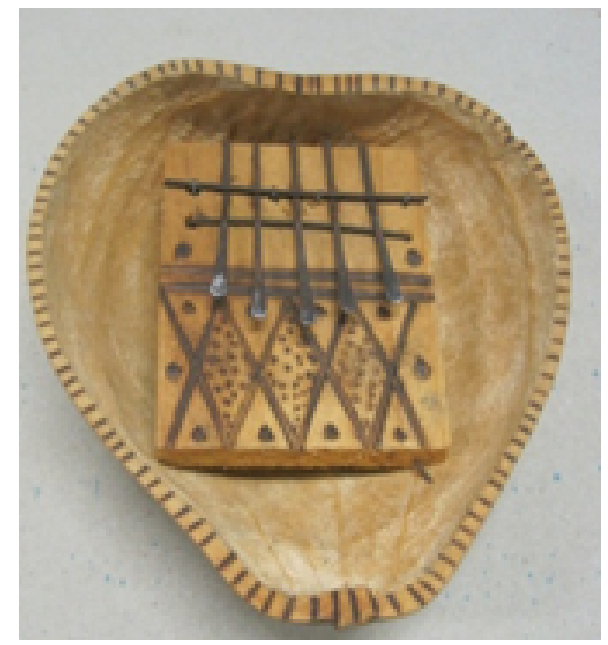

Figura 12 - Kalimba ou Karimba ( SILAMBO, 2011).

Vários pesquisadores como Tracey (1989) e Silambo (2012), apontam que a Karimba ou Kalimba é geralmente um instrumento secular, pelo fato de que ele não é comumente usado nas cerimônias de evocação dos espíritos ancestrais. Outros olhares exploram que "o repertório da pequena Karimba é orientado em grande parte para acompanhar as danças da exposição de Shangara, realizadas para relaxar em festas de bebidas locais após um longo dia de trabalho no campo (BERLINER, 1978, p. 33) . $^{50}$.

$\mathrm{O}$ primeiro morfema do nome deste instrumento é $k a$ - que de acordo com Williams (2000) é um prefixo diminutivo que indica tratar-se de um instrumento pequeno relativamente aos outros da mesma família. Com base nessa redução "em algumas partes de Tanzânia e Zanzibar, os lamelofones são chamados de marimba madogo que significa uma pequena marimba" (KAUFFMAN, 1980, p. 497) ${ }^{51}$.

Outros pesquisadores demonstram que a Kalimba para além de possuir um tamanho menor, ela constitui a base de iniciação de forma que "os tipos de Kalimba e Ndimba são tocados em vários contextos de mesmas localidades no norte do Zambeze, com a indicação de que há uma progressão do primeiro para o segundo; ou seja, Kalimba é usada por amadores e a Mbira Ndimba por músicos profissionais (TRACEY, 1972, p. 99-100; 1974, p. 3, tradução minha $)^{52}$. O Nigeriano Meki Nzewu traduz essa ideia da seguinte maneira:

Algumas culturas têm instrumentos musicais designados como instrumentos infantis. As crianças normalmente constroem esses instrumentos sozinhas e as usam para adquirir a habilidade de performance e exercícios individuais ou em grupo de

49 Idiofone tradicional de percussão que pode ser encontrado em Moçambique.

50 The small Karimba's repertory is oriented largely toward accompanying the Shangara exhibition dances performed for relaxation at beer parties following a long day's work in the field (BERLINER, 1978, p. 33).

51 "In other parts of Tanzania and Zanzibar, lamellophones are called marimba madogo, which means 'small marimba"" (KAUFFMAN, 1980, p. 497).

52 "The kalimba and the ndimba types are played in several of the same localities to the north of the Zambezi, with the indication that there is a progression from the first to the second; the kalimba is used by 'amateurs', the ndimba by 'professionals"” (TRACEY, TRACEY, 1972, p. 99-100; 1974, p. 3). 
criatividade que eventualmente os qualificarão para recrutamento em grupos adultos, mesmo em uma idade muito jovem. Os instrumentos musicais das crianças são menos duráveis e são réplicas menores de instrumentos adultos. Eles são feitos de materiais baratos e às vezes perecíveis. Como tal, a qualidade do som pode não ser tão boa quanto a [dos instrumentos dos] adultos (NZEWU, 2007, p. 81$)^{53}$.

Esta colocação mostra que o peso da madeira e a flexibilidade do arame são qualidades a serem consideradas na fabricação e afinação da Mbira de acordo com a idade do indivíduo. O etnomusicólogo Tracey através de dois artigos $(1972,1974)$ analisa o processo de afinação e concluiu que a Kalimba é o progenitor comum de vários tipos de Mbira encontrados pela África por demonstrar uma estrutura pentatônica contida em quase todos seus tipos, o que pressupõe uma estrutura básica usada no desvio das notas desta família de instrumentos.

A terminologia deste instrumento apresenta uma permutação do L e R. De acordo com o etnomusicólogo moçambicano Sitoe (2011) e outras fontes orais, alguns povos da zona centro do país (províncias de Tete, Zambézia, Manica e Sofala), tais como os Vashona, Vandaus, Vasenas fazem a alternância entre as consoantes "L" e "R", o que causa essas alterações (SILAMBO, 2012, p. 24). Como confirma Kubik (1980, p. 681-682) os fonemas "R" e "L" são permutáveis em muitas línguas bantu, por isso varimba torna-se valimba, karimba torna-se kalimba, chirimba torna-se chilimba e marimba torna-se malimba ${ }^{54}$.

Segundo as normas das línguas bantu "o tema básico nestas designações é -rimba ou -limba que se refere a uma nota ou tecla da Mbira ou xilofone, no entanto "marimba ou malim$b a$ " são os plurais de rimba ou limba (notas, teclas), respectivamente, pois ma é o prefixo plural de $r i$ ou li classe nominal a que rimba pertence (SILAMBO, 2012, p. 24).

Existe outro tema básico que se originou nas línguas bantu da área mais baixa do Rio Zambeze que é o -Sansi / -Sanji / -Sanzi. Este tema estava originalmente concentrado no sudeste da África, no entanto, mais tarde, espalhou-se pela África Central na República Democrática de Congo, Angola e países vizinhos. No Malawi, entre os Manyanja e Chewa, o nome Sansi é usado, enquanto os Vanyungwé em Moçambique usam o termo Nsansi.

Outros termos do tema são Thishanji (Namíbia), Ndandi (Zâmbia), Kisanji, Ocisanji, Cisanzi (Angola) e Sanji na República Centro-Africana. O outro tema básico difundido na África Central em países como Congo e Angola é -Kembe, podendo ser exemplificado por Likembe (GUMBORESHUMBA, 2009, p. 21-22). No entanto, deve-se notar que existem outros nomes da Mbira que ficam fora dos temas proeminentes. Por exemplo, a Mbira feita de palmeira de ráfia entre os Vavute no centro dos Camarões é conhecido como timbrh, no nordeste da Namíbia existe o Kangombyo, no centro da Zâmbia o termo difundido é kankobele e no norte de Moçambique usa-se o termo Xitata (GUMBORESHUMBA, 2009, p. 21-22). Desta forma, as características fonéticas de alguns povos, também, podem influenciar na terminologia da Mbira.

53 Some cultures have music instruments designated as children's instruments. Children normally construct such instruments by themselves, and use them to acquire the performance skill and self- or group-exercises in creativity that would eventually qualify them for recruitment into adult groups even at a very young age. Children's music instruments are less durable, and are smaller replicas of adult instruments. They are fashioned out of cheap and sometimes perishable materials. As such the sound quality may not be as good as that of adult species (NZEWU, 2007, p. 81).

54 "The phonemes " $R$ " and "L" are interchangeable in most Bantu languages, so marimba becomes malimba , karimba becomes kalimba , and mbira becomes mbila” (KUBIK, 1980b, p. 681-682). 
Portanto, existem tantas terminologias para estudar na música africana em seus próprios termos. Os termos do discurso musical africano são precisamente aqueles que vinculam o som a outros domínios da experiência humana. A linguagem que usamos para construir a música é uma linguagem que já incorpora conexões da música a outros domínios da cultura e da experiência cotidiana seja ela boa ou má, alta ou baixa, estável ou instável, grande ou pequena, equilibrada e desequilibrada, tudo isto dá materialidade e estrutura para a composição da música e definição da cultura.

"Afinal, os instrumentos musicais são tão simbólicos e emblemáticos dos povos e dos lugares quanto qualquer outro fenômeno musical" (DAWE, 2003, p. 278), interagindo com as realidades culturais de seu contexto, dialogando e reinventando seus usos, funções, valores, estruturas físicas, tímbricas e sonoros. A Mbira, tal como o Tambor, é um instrumento existente há milhões de anos atrás, e se faz presente em muitas culturas, independentemente de cor e nação. Sua estrutura física depende de cada cultura e do contexto que o envolve, sendo distintos os aspectos tamanhos, formatos, as funções e o som produzido (SANTOS, 2015, p. 48).

Consequentemente, existem vários fatores que contribuem para a atribuição das terminologias dos instrumentos musicais tradicionais africanos destacando a matéria-prima usada na sua fabricação, local da sua origem, atividade a que se relaciona (uso e função), instituição onde é fabricada ou ensinada, timbre do instrumento, características linguísticas, tamanho do instrumento entre outros. Cada intersecção gerada nos cruzamentos [deste fatores] compreende-se como uma fronteira que ressalta a emergência de outros caminhos para a invenção e releitura do mundo (RUFINO, 2016, p. 59).

Considerar esses fatores em pesquisa das terminologias de Mbira significa desenvolver práticas emancipatórias decoloniais, reconceitualizando a forma da democracia do universalismo ocidental e demonstrando que a decolonialidade não se reduz aos acontecimentos jurídico-políticos, mas segue um processo de ressignificação em longo prazo.

Nessa ótica, na consolidação dos estudos sobre as terminologias da Mbira encontro a chave para a compreensão da constituição essencial das sociedades humanas nas suas especificidades africanas. Portanto, todos os princípios terminológicos estão contidos na unidade compreensiva da Música de Mbira, pertencendo e estruturando-a, e sobretudo eles são a música de Mbira. Em vista disso, "os instrumentos musicais têm significados muito diferentes em suas culturas de proveniência daqueles que são investidos neles em museus", [ou outros locais ](DAWE, 2003, p. 281).

A Mbira Africana, fabricada e tocado pelos africanos faz parte de uma herança cultural única. "O instrumento é usado em cerimônias e práticas rituais que são completamente moldadas pela experiência, pensamentos, habilidades, necessidades e desejos [africanos], e tem grande importância como emblema e marcador de identidade étnica e cultural" (DAWE, 2003 , p. 281). Finalizo internalizando o antropólogo Victor Witter Turner $(1991$, p. 6) que acende: Nas ciências sociais em geral está se tornando amplamente reconhecido que as crenças e práticas culturais passam a ser vistas como chaves decisivas para a compreensão de como as pessoas pensam e sentem sobre suas vivências e sobre os ambientes naturais e sociais em que operam. 


\section{CONSIDERAÇÕES FINAIS}

Os países da África já foram "descolonizados”, mas lamentavelmente a colonialidade permanece centro do poder no saber, depreciando o património histórico (linguagem, hábitos, costumes, moral, etc.) da humanidade. É impossível descolonizar por total o mundo colonizado, pois as marcas indeléveis que constituem a colonialidade ainda são demasiadamente fortes no mundo atual, todavia é preciso demonstrar práticas ainda vivas que auxiliam a compreensão mais global da humanidade, entendendo que "toda tradição musical tem suas zonas únicas de complexidade, sofisticação e significado social [...]” (IVEY, 2007, p. 19).

Nesse sentido, o poder não funcionaria se fosse exercido unicamente por burgueses sobre proletários, por brancos sobre indígenas, por pais sobre filhos, porque todas essas relações se entrelaçam umas com as outras, conseguindo, cada uma, uma eficácia que sozinha nunca alcançaria (CANCLINI, 2008). Essa sobreposição ou entrelaçamentos não implica uma forma de dominação do outro. O que mais conta é a fórmula como os nomes, situações e fios costuram a humanidade. Diz o ditado "De uma mão, lava a outra", compreendendo que toda terminologia é importante de acordo com o seu propósito. Tudo isto nos ajuda a compreender e fazer o mundo melhor.

Assim, as reflexões críticas sobre as culturas não centradas na Europa contribuem com aspirações democráticas no planeta e correspondem as aflições da nossa atração pelo passado, a celebração das experiências dos sujeitos locais, bem como a consolidação de "movimentos sociais que desafiem o sistema numa insurgência revolucionária que complemente, amplie e então repudie um Iluminismo europeu incompleto e codificado racialmente" (GILROY, 2001, p. 16).

O empreendimento desenvolvido aqui focou na valorização como fator de resistência e estética cultural africana bem como a construção da sua identidade cultural, tendo em mente que as terminologias da Mbira constituem histórias esquecidas de saber que representam características linguísticas de um sujeito ou povo, prática ou tradição, espaço ou etnia, época, matéria-prima, atividades cotidianas, instituições, timbre do instrumento, entre outros perfis úteis para construção humana.

Este saber precisa ser dialogado com o que têm sido construído sobre a Mbira, mas para tal precisamos voltar do ponto zero e deixar claro o local de onde esse saber é produzido. É preciso fazer uma observação e abordagem intensas dentro do contexto Africano, porque essa história é feita por africanos e tais subordinados podem falar e ser ouvidos. A função do pesquisador, nesse clímax, deve ser interpretativa, compreendendo uma leitura africana da experiência africana, da terminologia africana, uma terminologia que eles moldam, vivenciam e compartilham como uma força de uma determinada manifestação cultural.

Ao olhar a produção do conhecimento nesse prisma, estaremos a dar voz aos sujeitos para enunciar suas práticas, vivências, construções, costumes entre outros aspectos significativos que auxiliam o conhecimento hegemónico. No entanto, é preciso voltar no passado para neste presente desenhar o nosso futuro, assumindo que a África tem história, instrumentos, sujeitos, práticas, terminologias, espaços, tradições, costumes importantes no crescimento da Humanidade. Neste sentido, a tarefa de pesquisar, publicar e divulgar sobre as terminologias da Mbira carece de esforço conjunto de muitos investigadores, pois, na verdade, cada tipo de Mbira apresenta uma especificidade estrutural e cultural para ser buscada e entendida. 
Limitei-me por apresentar e discutir algumas terminologias da Mbira, na expectativa de que, em breve, sejam completados por outros dados relevantes que contemplem profundamente xitata, kasasi, sansi; ringa, rissange, quisanje, matepe, hera, mbira dzaVandau, dipila, ndimba, ikembe, likembe que, como vimos, são outras terminologias usadas em Moçambique, Angola, Zimbabwe, África de Sul e Congo. Haja consciência que todo elemento simbólico está relacionado a algum elemento empírico da experiência, como revelaram claramente algumas interpretações feitas.

Sugiro que escutemos epistemologias de culturas africanas que exploram diferentes entendimentos da produção de conhecimento, pois a força dessas culturas se expressa por meio do significado de relações das suas produções, elementos e hábitos diversos. Ao nos envolvermos com tais epistemologias, deixamos o universalismo no estágio anterior e abrimo-nos justamente e democraticamente para múltiplas verdades e passamos a entender que a "diversidade é, de certa forma, uma espécie de palavra gentil e educada para anti-racismo, anti-sexismo, anti-ódio" (CHÁVEZ; SKELCHY, 2019, p. 137).

Valeria a pena decolonizar as terminologias da Mbira? A minha resposta é sim, pois a Mbira traz consigo a história de como a sociedade africana se formou e como a cultura se auto identifica. Qual é a sua? Ainda quer continuar nessa? Devemos nos despedir com prazer daquela fase de ouro, sim, pois por detrás das terminologias eurocêntricas estava um colonialismo que é inaceitável hoje. Porém, não será possível qualquer despedida ou mudança nas terminologias da Mbira se não tivermos coragem de mudar a nossa vestimenta modelada e se não estivermos preparados a assumir a diversidade das expressões que caracterizam este contexto musical. É chegado o momento de encararmos esse desafio de modo a criar as rupturas necessárias para a construção da humanidade. Espero não ser acusado de pregar o ódio e agressividade contra a Arte Ocidental pelo simples fato denunciar o segredo dos diferentes tipos de Mbira.

\section{WOULD IT BE WORTH TO DECOLONIZE MBIRA'S TERMINOLOGIES?}

ABSTRACT: The nomenclature of traditional African musical instruments in contemporary times contemplates a diversity of issues that lead us reflect. Among the important discussions that permeate the attribution of terminologies to these musical instruments, the context of their production (human subjects, situations, spaces, times, sounds, experiences, narratives, and memories) has occupied a prominent place. This article reflects on aspects that have been considered in the attribution of the Mbira nomenclature (traditional African musical instrument), pointing out perspectives that may justify the redefinition of terminologies due to their implication in the contemplative construction of humanity. The work is based on bibliographic research, participant observation, semi-structured interview, and the author's experiences as a Mbira scholar and performer. Based on the discussions held, the text points out important aspects that justify the valorization of the means of its production in the attribution of the terminologies of the African instruments, providing an adjustment of the ideological products of the world thought about the "other".

KEYWORDS: Mbira. Terminology. Coloniality. Decoloniality.

\section{REFERÊNCIAS}

AGAWU, Victor Kofi. African Music as Text. Research in African Literatures, Vol. 32, No. 2, The Landscape of African Music. 2001. p. 8-16. Indiana University Press. Disponível em: https://www. jstor.org/stable/3820902. Acesso em: 13 Fev. 2020. 
BERLINER, Paul. The soul of Mbira: music and traditions of the Shona people of Zimbabwe. Berkeley, $\mathrm{CA}^{55}$ : University of California Press, 1978.

BLACKING, John. Patterns of Nsenga kalimba. African Music: Journal of the International Library of African Music, Makhanda, RSA, v. 2, n. 4, 1961. p. 26-43.

BOHMAN, Philip Vilas. World Music at the "End of History". Ethnomusicology, Vol. 46, No. 1, 2002, pp. 1-32. University of Illinois Press on behalf of Society for Ethnomusicology. Disponível em: http://www.jstor.org/stable/852806 Acesso em: 20 Mar. 2020.

CABRAL. Amilcar. The role of culture in the battle for independence. In 'Portuguese' Africa the struggle for independence. Editores - Sandy Koffler, René Caloz, Olga Rodel, Paris: UNESCO COURIER . 1973. p. 12-20.

CANCLINI, Néstor García. Culturas híbridas - estratégias para entrar y salir de la modernidad. $1^{\text {a }}$ Ed. $4^{\mathrm{a}}$ reimpressão. Buenos Aires: Paidós, 2008.

CARVALHO, Leandro. Idade do Ferro na África. 2020. Disponível em: https://alunosonline.uol. com.br/historia/idade-ferro-na-africa.html. Acesso em: 23 Fev. 2020.

CASTRO-GÓMEZ, Santiago; GROSFOGUEL, Ramón (Org.). El giro decolonial: reflexiones para una diversidad epistémica más allá del capitalismo global. Bogotá: Universidad Javeriana-Instituto Pensar, Universidad Central-IESCO, Siglo del Hombre Editores, 2007. Disponível em: <http:// biblioteca.clacso.edu.ar/clacso/se/20140506032333/eje1-7.pdf>. Acesso em: 11 nov. 2019.

CGTN AFRICA. Faces Of Africa - Chief Obasanjo at your service. 2014. Disponível em: https:// www.youtube.com/watch?v=Azj7qk6RQdQ. Acesso em: 15 Jan. 2020.

CHÁVEZ, Luis. SKELCHY, Russell P. Decolonization for Ethnomusicology and Music Studies in Higher Education. Action, Criticism, and Theory for Music Education. September 2019, Volume 18 (3): 115-43. Disponível em: https://doi.org/10.22176/act18.3.115 Acesso em: 10 Jun. 2020.

CURADO, Adriano. O que foi a Conferência de Berlim e como ela dividiu a África. 2018. Dispónivel em: https://conhecimentocientifico.r7.com/o-que-foi-a-conferencia-de-berlim-e-como-ela-dividiu-aafrica/ acesso em: 11 Nov. 2019.

DAWE, Kevin. The Cultural Study of Musical Instruments. In The cultural study of music: a critical introduction. Editado por CLAYTON, Martin; HERBERT, Trevor; MIDDLETON, Richard. New York: Routledge. 2003. p. 278-287.

DELGADO, Carolina Santamaría. El bambuco y los saberes mestizos: academia y colonialidad del poder en los estudios musicales latinoamericanos. In: CASTRO-GÓMEZ, Santiago; GROSFOGUEL, Ramón (Org.). El giro decolonial: reflexiones para una diversidad epistémica más allá del capitalismo global. Bogotá: Universidad Javeriana-Instituto Pensar, Universidad Central-IESCO, Siglo del Hombre Editores, 2007. p. 195-215. Disponível em: <http://biblioteca.clacso.edu.ar/clacso/ se/20140506032333/eje1-7.pdf>. Acesso em: 11 nov. 2019.

DIAS, Margot. Idiofones dedilhados. In _ _ Instrumentos musicais de Moçambique. Lisboa, POR: IICT $^{56}$; Centro de Antropologia Cultural e Social,1986. p. 75-102.

DUARTE, Maria da Luz Teixeira (Coord.) $)^{57}$. Catálogo dos instrumentos musicais de Moçambique. Maputo, MOZ: Ministério da Educação e Cultura, 1980.

DUSSEL, Enrique. Europa, modernidade e eurocentrismo. in Lander, Edgardo (comp.) A colonialidade do saber: eurocentrismo e ciências sociais. Perspectivas latino-americanas, 2005. Pp. 24-32. Disponível em: http://bibliotecavirtual.clacso.org.ar/ Acesso em: 27 Mar. 2020.

FLÓREZ, Juliana Flórez. Lectura no eurocéntrica de los movimientos sociales latinoamericanos: Las claves analíticas del proyecto modernidad/colonialidad. In: CASTRO-GÓMEZ, Santiago; GROSFOGUEL, Ramón (Org.). El giro decolonial: reflexiones para una diversidad epistémica más allá del capitalismo global. Bogotá: Universidad Javeriana-Instituto Pensar, Universidad Central-

55 California (CA).

56 Instituto de Investigação Científica Tropical (IICT).

57 Coordenadora (Coord.). 
IESCO, Siglo del Hombre Editores, 2007. p. 93-126. Disponível em: <http://biblioteca.clacso.edu. ar/clacso/se/20140506032333/eje1-7.pdf>. Acesso em: 11 nov. 2019.

FORKEL, Johann Nicolaus. Allgemeine Geschichte der Musik (Leipzig, 1788). Facsimile ed. Editado por Othmar Wessely. Graz, Austria: Akademische Druck und Verlagsanstalt. 1967.

FRITZDOBBERT. Piano. 2017. Dispónivel em: http://blog.fritzdobbert.com.br/tudo-sobre-piano/ muito-mais-que-uma-simples-tampa-de-piano/ acesso em: 11 Nov. 2019.

GILROY, Paul. O Atlântico negro: modernidade e dupla consciência / Paul Gilroy; tradução de Cid Knipel Moreira. - São Paulo: Ed. 34; Rio de janeiro: Universidade Cândido Mendes, Centro de Estudos Afro-Asiáticos, 2001.

GÓMEZ, Santiago Castro. Decolonizar la universidad: La hybris del punto cero y el diálogo de saberes. In: CASTRO-GÓMEZ, Santiago; GROSFOGUEL, Ramón (Org.). E1 giro decolonial: reflexiones para una diversidad epistémica más allá del capitalismo global. Bogotá: Universidad Javeriana-Instituto Pensar, Universidad Central-IESCO, Siglo del Hombre Editores, 2007. p.93-126. Disponível em: <http://biblioteca.clacso.edu.ar/clacso/se/20140506032333/eje1-7.pdf>. Acesso em: 11 nov. 2019.

; GROSFOGUEL, Ramón. Giro decolonial, teoría crítica y pensamiento heterárquico. In: CASTRO-GÓMEZ, Santiago; GROSFOGUEL, Ramón (Org.). E1 giro decolonial: reflexiones para una diversidad epistémica más allá del capitalismo global. Bogotá: Universidad Javeriana-Instituto Pensar, Universidad Central-IESCO, Siglo del Hombre Editores, 2007. p. 93-126. Disponível em: <http://biblioteca.clacso.edu.ar/clacso/se/20140506032333/eje1-7.pdf>. Acesso em: 11 nov. 2019. GEERTZ, Clifford. The interpretation of cultures. New York, USA: Basic Books, 1973.

GUMBORESHUMBA, Laina. Understanding form and technique: Andrew tracey's contribution to knowledge of lamellophone (Mbira) music of Southern Africa. 2009. 125 f. Dissertação (Mestrado em etnomusicologia) - Rhodes University, África de Sul. 2009.

HELB M. Melhores Discursos de Samora Machel. 2019. Disponível em:https://www.youtube.com/ watch?v=U9Fa16fVzJo. Acesso em: 21 Fev. 2020.

IVEY, Bill. Ethnomusicology and the Twenty-First Century Music Scene. Ethnomusicology, Vol. 53, No. 1, 2009, pp. 18-31. University of Illinois Press on behalf of Society for Ethnomusicology. Disponível em: http://www.jstor.o. Acesso em: 11 Mar. 2020.

JONES, A. M. The kalimba of the Lala Tribe, Northern Rhodesia. Africa: Journal of the International African Institute, Cambridge, UK, v. 20, n. 4, 1950. p. 324-334.

KAUFFMAN, Robert. Multi-part relationships in the Shona Music of Rhodesia. 1970. $579 \mathrm{f}$. Dissertation (Ph D in Ethnomusicology) - University of California, Los Angeles, CA, 1970.

. Lamellaphone: 1. In The New Grove Dictionary of Music and Musicians, ed.

Stanley Sadie, 10: 497. London: Macmillan.1980.

KUBIK, Gerhard. Marimba. In The New Grove Dictionary of Music and Musicians, ed. Stanley Sadie, 11:681-682. London: Macmillan.1980.

. Kalimba-Nsansi-Mbira. Lamellophone in Afrika. With CD. Berlin: Museum für Völkerkunde. 1998.

Lamelofones do Museu Nacional de Etnologia. Lisboa, POR: MC ${ }^{58}$; IPM ${ }^{59}$;

$\mathrm{MNE}^{60}, 2002$.

Jazz transatlantic. The African undercurrent in twentieth -century jazz culture.

University press Mississippi/Jackson. 2017. I volume.

MACOO, Ozias. [Mbira]. 2019. 1 fotografia, color.

MARAIRE, Dumisani Abraham. The Nyunga Nyunga Mbira. Portland: Swing Trade, 1991.

MCCOLLUM, Jonathan; HEBERT, David G.. Foundations of Historical Ethnomusicology. In

58 Ministério da Cultura de Portugal (MC).

59 Instituto Português de Museus (IPM).

60 Museu Nacional de Etnologia (MNE). 
Theory and method in historical ethnomusicology / editado por Jonathan McCollum and David G. Hebert. United Kingdom: Lexington Books, 2014.

MERRIAM, Alan P. The Anthropology of Music. Chicago: Northwestern University Press, 1964. MIGNOLO, Walter D.. El pensamiento decolonial: desprendimiento y apertura. Un manifiesto. In: CASTRO-GÓMEZ, Santiago; GROSFOGUEL, Ramón (Org.). E1 giro decolonial: reflexiones para una diversidad epistémica más allá del capitalismo global. Bogotá: Universidad Javeriana-Instituto Pensar, Universidad Central-IESCO, Siglo del Hombre Editores, 2007. p.93-126. Disponível em: <http://biblioteca.clacso.edu.ar/clacso/se/20140506032333/eje1-7.pdf>. Acesso em: 11 nov. 2019. MIGNOLO, Walter D. Epistemic disobedience, independent thought and decolonial freedom. Theory, culture \& society, v. 26, n. 7-8, p. 159-181, 2009. Disponível em: http://waltermignolo.com/ wp-content/uploads/2013/03/epistemicdisobedience-2.pdf Acesso em: 24 Mar. 2019.

MUKHAMBIRA, Oficina. [Mbira dzaVadzimu]. 2011.1 fotografia, color.

MUCAVEL, Ivan Johan. [Mbira Nyunganyunga]. 2018. 1 fotografia, color.

. Entrevista semi-estruturada. 2019a.

[Mbira Dzava-Nyungué Moto M'djindja]. 2019b. 1 fotografia, color.

MUKHAVELE, Luka. Anxjelina. 2019a. 1 vídeo no YouTube. Disponível em:<https://youtu. be/6bjSxjU46J8>. Acesso em: 11 Nov. 2019.

. [Mbira Ndhondhoza - Workshop realizado na Escola de Comunicação e Artes]. Maputo, MOZ, 2019b. 1 fotografia, color.

MWANGOLE TV. 10 MOMENTOS PARA ENTENDER JONAS SAVIMBI - EP4. 2020. Disponível em: https://www.youtube.com/watch?v=RIOAxvR0LTQ. Acesso em: 22 Jan. 2020.

NGUNGA, Armindo Saúl Atelela. Introdução à linguística Bantu. Maputo: Imprensa Universitária. 2004.

NKETIA, Kwabena John Hanson. The Music of Africa. London: Victor Gollancz.1979.

NZEWI, Meki. A CONTEMPORARY STUDY OF MUSICAL ARTS Informed by African IndIgenous knowledge systems. Pretoria: Centre for Indigenous Instrumental African Music and Dance (CIIAMDA). 2007. Volume 2.

PELINSKI, Ramón. Etnomusicología en la edad posmoderna. 2002. Disponível em.: https://www. scribd.com/document/316798646/Pelinski-Ramon-Etnomusicologia-en-La-Edad-Posmoderna. Acesso em 18 Mar. 2020.

QUEIROZ, Luis Ricardo siLva. Traços de colonialidade na educação superior em música do Brasil: análises a partir de uma trajetória de epistemicídios musicais e exclusões. REVISTA DA ABEM | Londrina | v.25 | n.39 | 132-159 | jul.dez. 2017a. Disponível em: http://abemeducacaomusical. com.br/revistas/revistaabem/index.php/revistaabem/article/view/726/501. Acesso em: 15 Nov. 2019.

. Formação intercultural em música: perspectivas para uma pedagogia do conflito e a erradicação de epistemicídios musicais. InterMeio: Revista do Programa de Pós-Graduação em Educação, Campo Grande, v. 23, n. 45, p. 99-124, 2017b. Disponível em: https://periodicos.ufms.br/ index.php/intm/article/view/5076. Acesso em: 11 Nov. 2019.

QUIJANO, Aníbal. Colonialidad del poder y clasificación social. In: CASTRO-GÓMEZ, Santiago; GROSFOGUEL, Ramón (Org.). El giro decolonial: reflexiones para una diversidad epistémica más allá del capitalismo global. Bogotá: Universidad Javeriana-Instituto Pensar, Universidad CentralIESCO, Siglo del Hombre Editores, 2007. p. 93-126. Disponível em: <http://biblioteca.clacso.edu.ar/ clacso/se/20140506032333/eje1-7.pdf>. Acesso em: 11 nov. 2019.

RICE, Timothy. Toward a Mediation of Field Methods and Field Experience in Ethnomusicology. In : MODELING ETHNOMUSICOLOGY. New York, NY: Oxford University Press, 2017. pp. 63-86.

RUFINO, Luiz. Performances afro-diaspóricas e decolonialidade: o saber corporal a partir de exu 
e suas encruzilhadas. Revista Antropolítica, n. 40, Niterói, p.54-80, 1. sem. 2016. Disponível em: https://periodicos.uff.br/antropolitica/article/download/41797/23790. Acesso em: 14 Jun. de 2020. SANTOS, Boaventura de Sousa; MENESES, Maria Paula. (Orgs.). Epistemologias do Sul. São Paulo: Cortez, 2010.

SANTOS, Edileusa. Dança de expressão negra: um novo olhar sobre o tambor. Repertório, Salvador, $\mathrm{n}^{\mathrm{o}}$ 24, p.47-55, 2015.1. Disponível em: https://portalseer.ufba.br/index.php/revteatro/article/ download/14828/10173 Acesso em: 16 Mai. 2020.

SILAMBO, Micas Orlando. [Kalimba de pinho exposta na Feira Agropecuária, Comercial e Industrial (FACIM)]. Marracuene, Maputo, Moçambique, 2011. 1 fotografia, color.

Análise organológica da Mbira Nyunganyunga em Moçambique: caso de Projeto Mukhambira. 2012a. 71 f. TCC (Monografia) - Escola de Comunicação e Artes, Universidade Eduardo Mondlane, Maputo, Moçambique, 2012.

O ensino e a aprendizagem da Mbira Nyunganyunga em sua dimensão técnica: uma pesquisa-ação com licenciandos em Música da UFRN. 2018. 258 f. Dissertação (Mestrado em Música) - Escola de Música, Universidade Federal do Rio Grande do Norte (UFRN), Natal, RN ${ }^{61}$ 2018.

SILVA, Flora Pereira da. (s.d ${ }^{62}$ ). Mbira, minha Mbira: Som sagrado, notas doces e música em transe. Dispónivel na página Afreaka em: http://www.afreaka.com.br/mbira-minha-mbira/. Acesso em: 24 Nov. 2019.

SITOE, Pedro Júlio. Entrevista semi-estruturada. 2011. Professor de Etnomusicologia e Mbira da Escola de Comunicação e Artes em Moçambique.

STONE, Sarah. A história da invenção do piano. 2015. Disponível em: https://gizmodo.uol.com. br/como-o-piano-foi-inventado/. Acesso em: 22 Fev. 2020.

TOMLINSON, Gary. Musicology, Anthropology, History in The cultural study of music: a critical introduction. Editado por CLAYTON, Martin; HERBERT, Trevor; MIDDLETON, Richard. New York: Routledge. 2003. p. 36-48.

TURNER, Victor Witter. The Ritual Process: Structure and Anti-Structure. New York: University Press. 7ed. 1991. Disponível em: https://www.academia.edu/25939967/Victor_Witter_Turner_ The_ritual_process_structure_and_anti-structure. Acesso em: 02 Fev. 2020.

TRACEY, Andrew. Mbira Music of Jege A.Tapera. African Music.1961. 2(4), 44-63.

. The Original African Mbira?. African Music. 1972. 5(2), 85-104.

The Family of the Mbira. Roodepoort: International Library of African Music. 1974.

Disponível em: sanweb.lib.msu.edu > DMC > African Journals > pdfs > juz003002002. Acesso em: 05 Dez. 2019.

The System of the Mbira. Symposium on Ethnomusicology. Andrew Tracey (Ed.), 4355. 1989. Grahamstown: International Library of Music, Rhodes University. Disponível em journal. ru.ac.za > index.php > africanmusic > article > view Acesso em: 11 Dez. 2019.

TRACEY, Hugh. The Mbira Class of African Instruments in Rhodesia (1932). African Music. 1969. 4 (3), 78-95.

WALSH, Catherine. Interculturalidad y colonialidad del poder. Un pensamiento y posicionamiento "otro" desde la diferencia colonial. In E1 giro decolonial: reflexiones para una diversidad epistémica más allá del capitalismo global / compiladores Santiago Castro-Gómez y Ramón Grosfoguel. - Bogotá: Siglo del Hombre Editores; Universidad Central, Instituto de Estudios Sociales Contemporáneos y Pontificia Universidad Javeriana, Instituto Pensar, 2007. p. 47-62.

WALSH, Catherine (Ed.). Pedagogías decoloniales: prácticas insurgentes de resistir, (re)existir y (re) vivir. Tomo I. Quito, Ecuador: Ediciones Abya-Yala, 2013.

61 Rio Grande do Norte (RN).

62 Este texto não apresenta o ano da publicação. 
WILLIAM, Rodney. Apropriação cultural/ Rodney William. - São Paulo: Pólen. 2019 (In Feminismos plurais/ Coordenação de Djamila Ribeiro). P. 68-89.

WILLIAMS, Michael. Mbira/Timbila, Karimba/Marimba: a look at some relationships between African Mbira and Marimba. 2000. Disponível em: $<$ http://bmichaelwilliams.com/ wp-content/ uploads/2013/02/PNMbiraTimbila.pdf>. Acesso em: 20 abr. 2012.

Data submissão: 07/05/2020

Data aprovação:17/07/2020 